\title{
SISTEMATIZACIÓN DE EXPERIENCIAS
}

"Diferentes miradas de una vivencia"

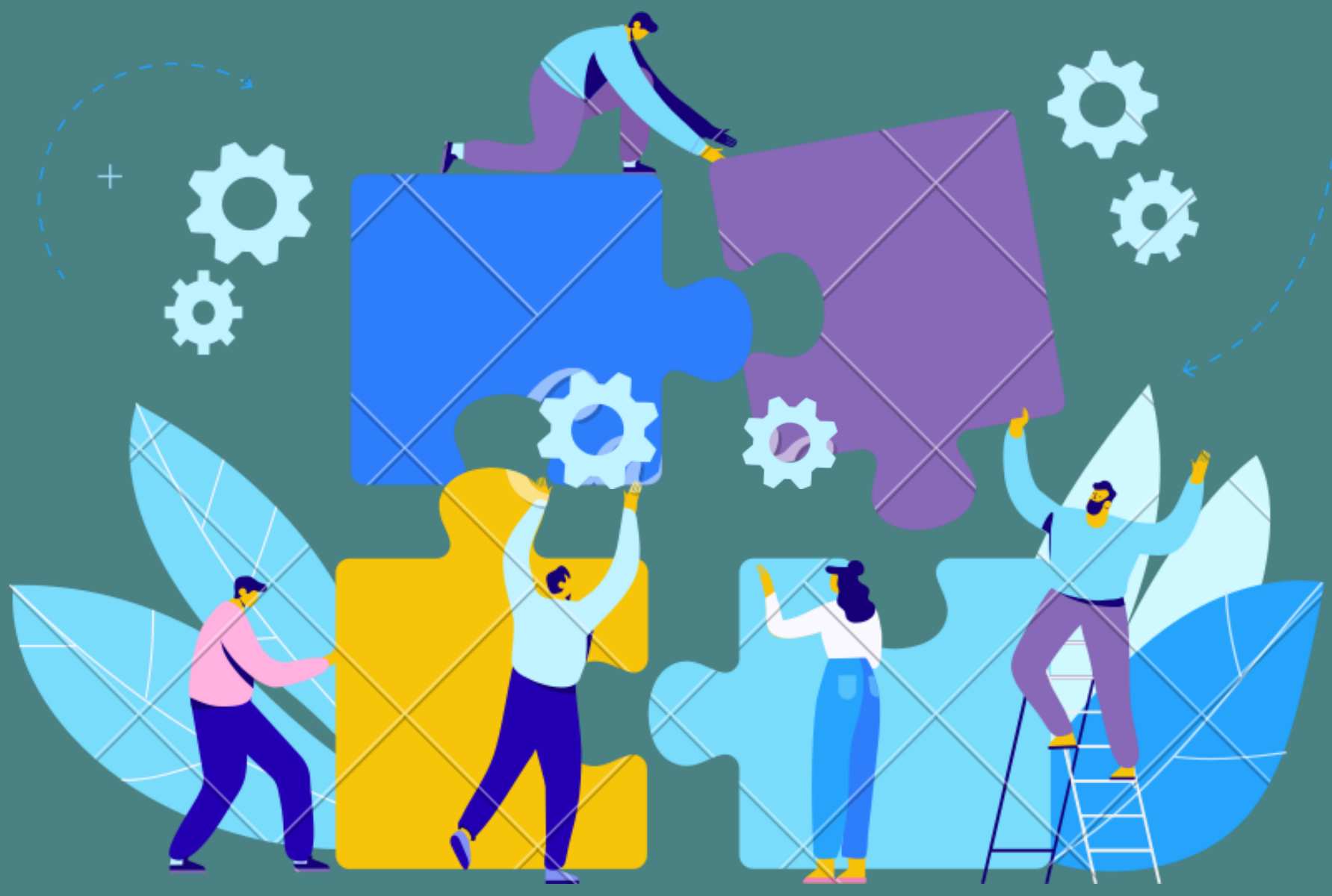

Carmen Aurora Sánchez

Jessica Lorena Pardo Juliana Dayana Barajas

María Paula Sánchez

Sonia AlejandraHernández Autores

Julie Alejandra Rojas

Compilador
ACREDITACIÓN INSTITUCIONAL DE ALTA CALIDAD MULTICAMPUS

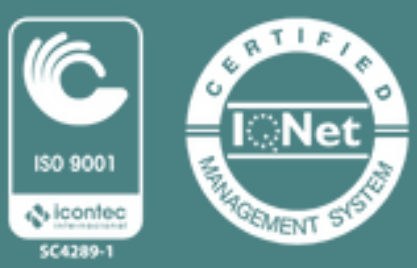




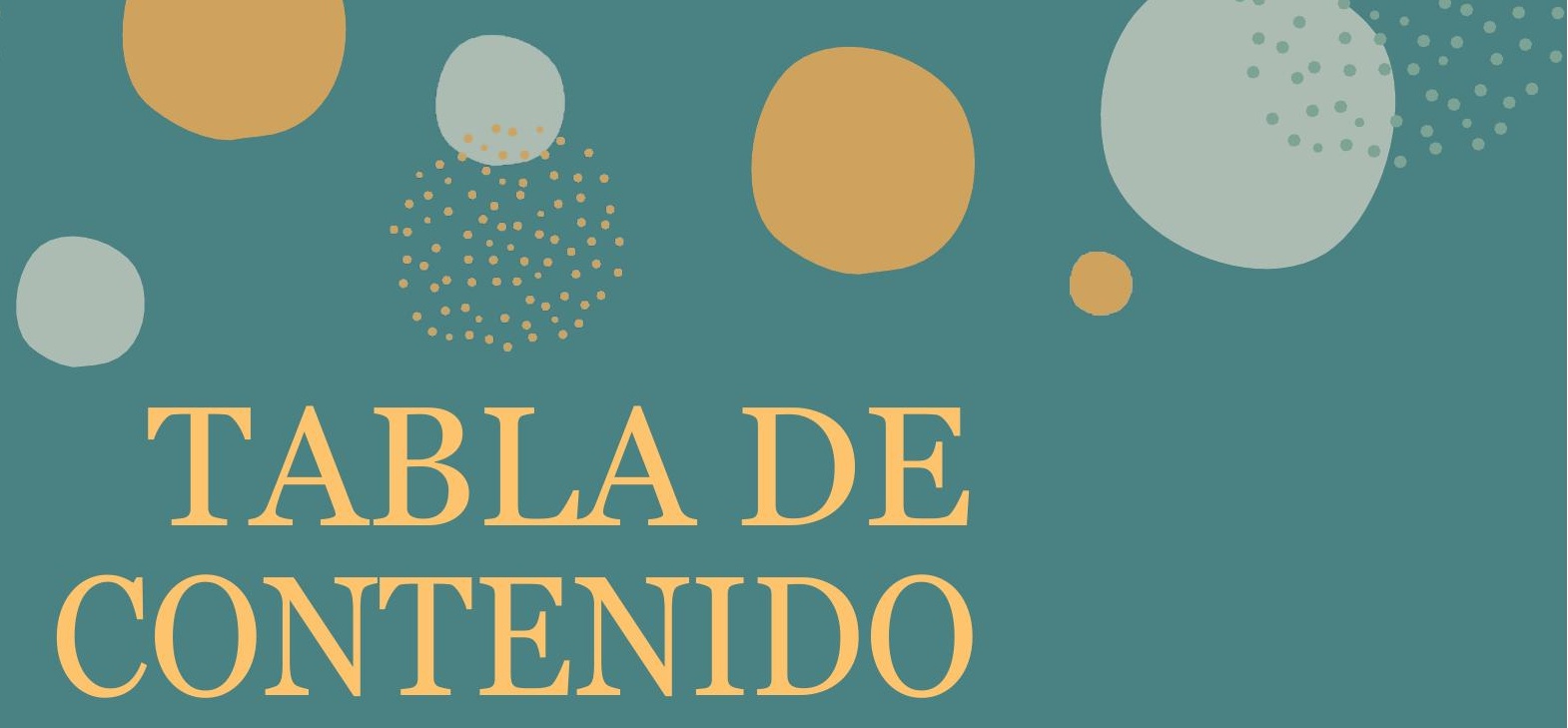

1. Introducción

2. Objetivo

3. Definición

4. Origen

5. Características de la Sistematización de experiencias

6. ¿Como sistematizar una experiencias?

- El punto de partida: La experiencia

Haber participado en la(s) experiencia(s).

Contar con registros de la(s) experiencia(s).

- Formular un plan de sistematización

¿Para qué queremos sistematizar? (Definir el objetivo).

¿Qué experiencia(s) queremos sistematizar? (Delimitar el objeto).

¿Qué aspectos centrales nos interesan más? (Precisar un eje de si stematización)

¿Qué fuentes de información tenemos y cuáles necesitamos?

¿Qué procedimiento concreto vamos a seguir y en qué tiempo?

- La recuperación del proceso vivido

Reconstruir la historia de la experiencia.

Ordenar y clasificar lainformación

- Las reflexiones de fondo

Procesos de análisis, síntesis einterrelaciones.

Interpretación crítica.

Los puntos de llegada

Formular conclusiones, recomendaciones y propuestas.

Estrategia para comunicar los aprendizajes y las proyecciones. 7.Técnicas

8.Ejemplos de sistematización de experiencias 


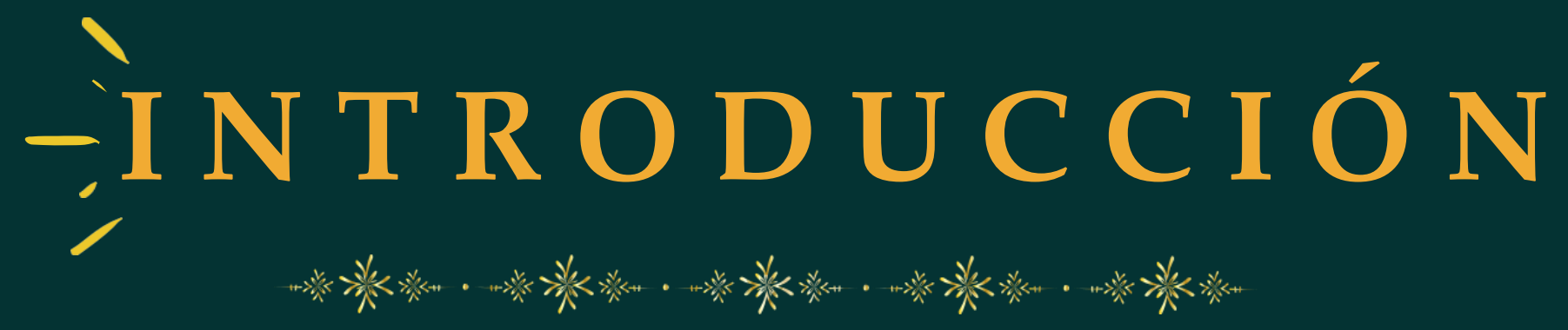

El presente trabajo se centra principalmente en la sistematización de experiencias, entendiéndose como la reconstrucción y reflexión analítica de las mismas mediante la cual se interpreta críticamente lo sucedido para comprenderlo.

La importancia de la sistematización de experiencias ha incrementado notoriamente en los últimos años, en diferentes disciplinas, prevaleciendo en

las áreas de intervención social, como salud, educación, proyectos de desarrollo, entre otros.
Incluso también se podría hablar de sistematización de experiencias en

el campo de capacitación agropecuaria y protección del medio ambiente. Por lo tanto, cada vez se valora más la necesidad de rescatar los aprendizajes de las experiencias prácticas que se adelantan en el campo de la acción cotidiana.

A lo largo de esta cartilla se explicarán detalladamentelas características que la rodean, su origen, las técnicas que utiliza y el proceso mediante el cual se logra, teniendo en cuenta que no es un ejercicio simplista que siga un modelo o una serie de pasos para alcanzar el objetivo, sino que es un proceso que exige pasión y disposición creativa.

\section{(Jara,2018) (canva,2020)}



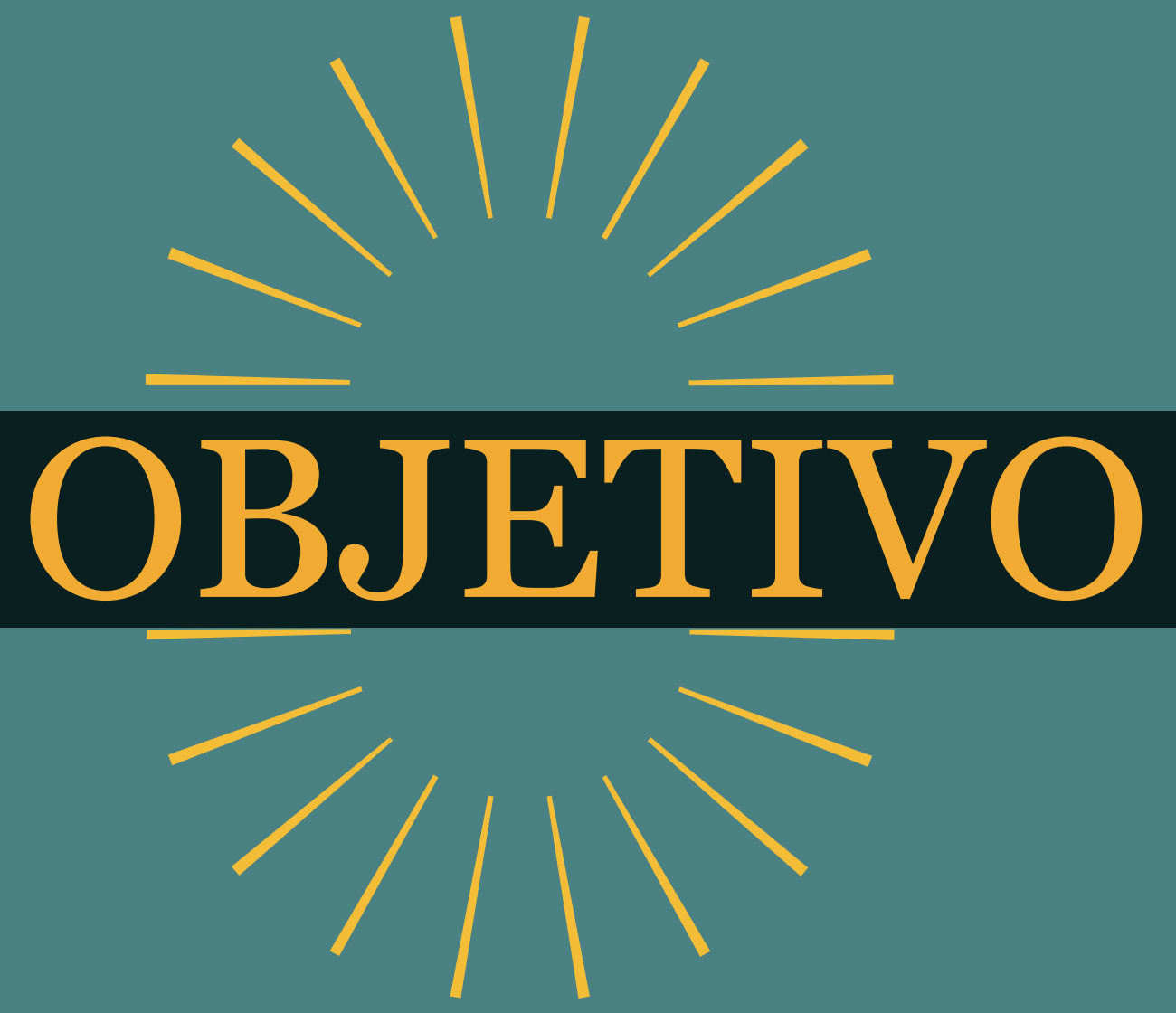

Explicar la sistematización de experiencias, su origen, sus características, cómo se aplica, y qué técnicas utiliza por medio de una cartilla didáctica que facilite la comprensión y el aprendizaje de este método de investigación. 


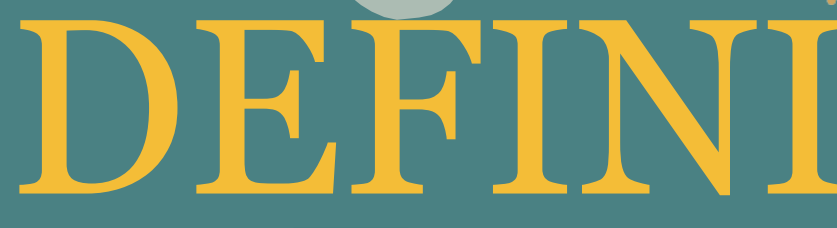

"La palabra sistematización en determinadas disciplinas se refiere principalmente. a clasificar,catalogar,ordenar datos e informaciones, sin embargo en el campo de educación popular y de trabajo en procesos sociales lo utilizamos en un sentido más amplio, referido no solo a datos o informaciones que se recogen si se ordenar sino a obtener aprendizaje critico". (Hollyday,2007).

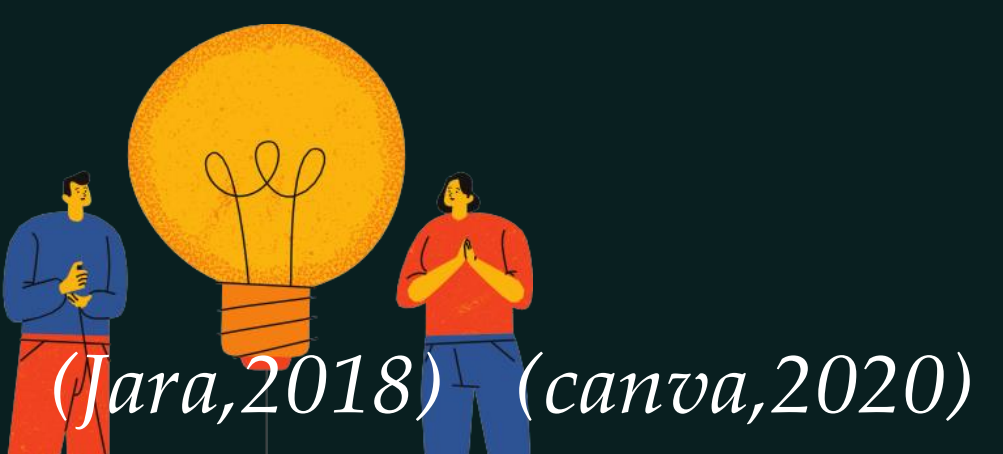




\section{DEFINICIONES}

"La sistematización de experie s es una interpretación crítica de una - varias experiencias que, apartr de su ordenamiento y reconstrucción. descubre o explicita la lógica del proceso, los factores que han intervenido en él, cómo se han relacionado entre sí y por qué lo han hecho de ese modo" (Expósito \& Gonzalo,2017)

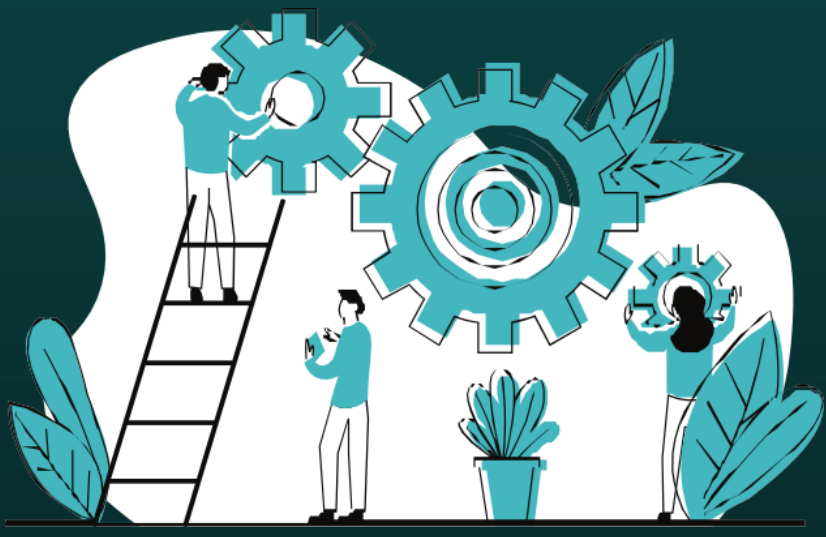
sus componentes teóricos.
prácticos, permite

"la sistematización como un proceso de recuperación tematización y apropiación determa práctica formativa sistémica, que al relacionar comprenderite a los sujetos $($ Jara,2018) (canva,2020) contextos"(R explicar los 1), 


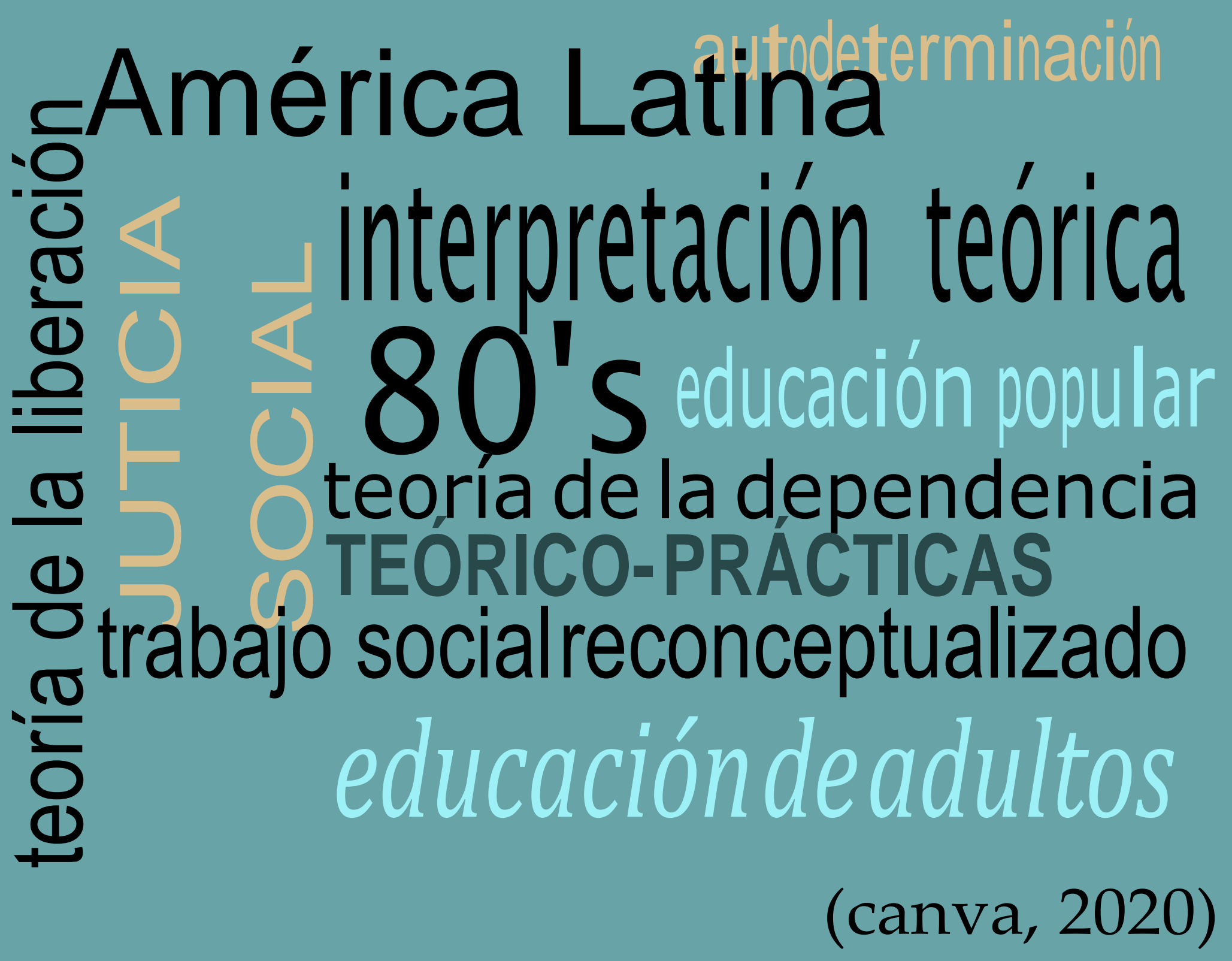




\section{¿DE DONDE SURGIÓ EL CONCEPTO DE SISTEMATIZACIÓN?}

El concepto de sistematización de experiencias ha surgido en América Latina como producto del esfuerzo por construir marcos propios de interpretación teórica desde las condiciones particulares de nuestra realidad.

En 1959, la Revolución cubana abrió un nuevo periodo histórico en "Nuestra América", como la llamaba Martí, demostrando que es posible romper el esquema de dominación colonial que se impuso a nuestros países desde la conquista española además, que era posible pensar desde la realidad específica de América Latina, un proyecto distinto de sociedad basado en la búsqueda de justicia social y autodeterminación.
La sistematización de experiencias nace a principios de la década de los 80 en un contexto de crisis socioeconómica en la mayoría de países de la región

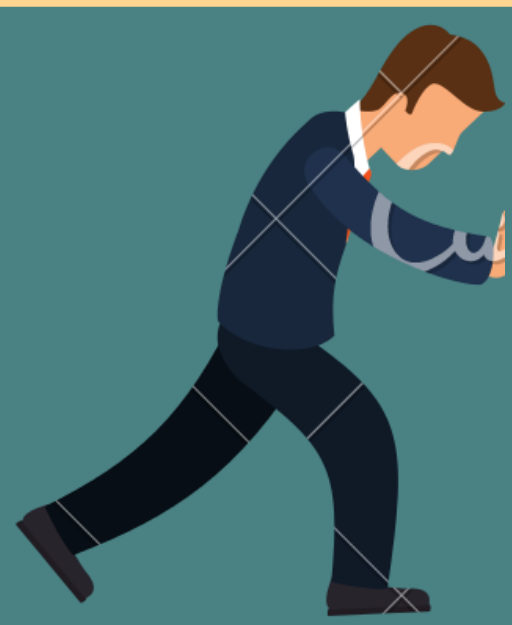

motivo por el cual se habla de los 80 como la "década perdida de América Latina" en el que el paradigma de la educación para el desarrollo desde la perspectiva de la teoría del capital humano estaba demostrando sus carencias. 


\section{durante los años ochenta...}

en estaépocala propuesta de la educación popular se

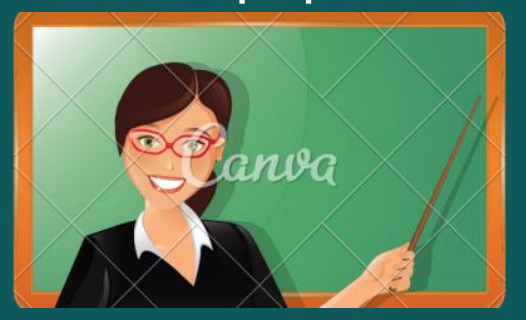

estaba difundiendo con éxito en el territorio latinoamericano

\section{era habitual que se asumiera}

esta propuesta

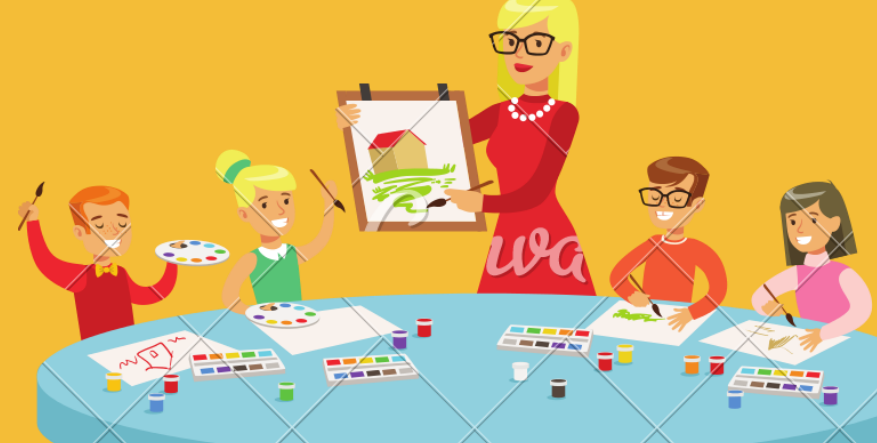

pedagógica desde diferentes

movimientos populares.

Entre otros casos, podríamos destacar su centralidad en la recién triunfante Revolución Sandinista, en las Comunidades de Población en

Resistencia guatemaltecas,

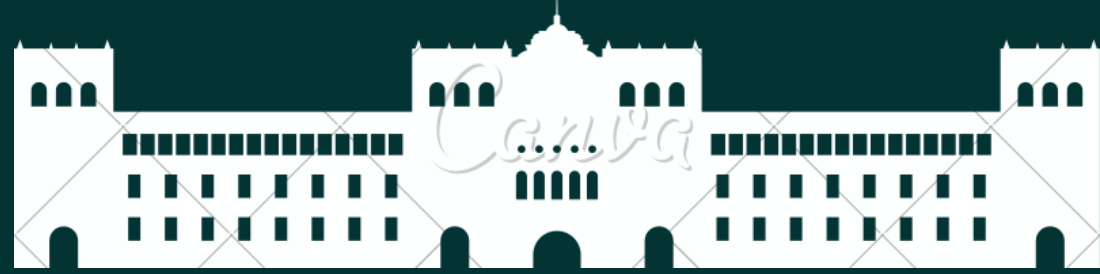

o en el desarrollo de organizaciones populares de Brasil de la trascendencia de la Central Unificada de Trabajadores (CUT) o del Movimiento de Trabajadores Rurales sin Tierra (MST). 


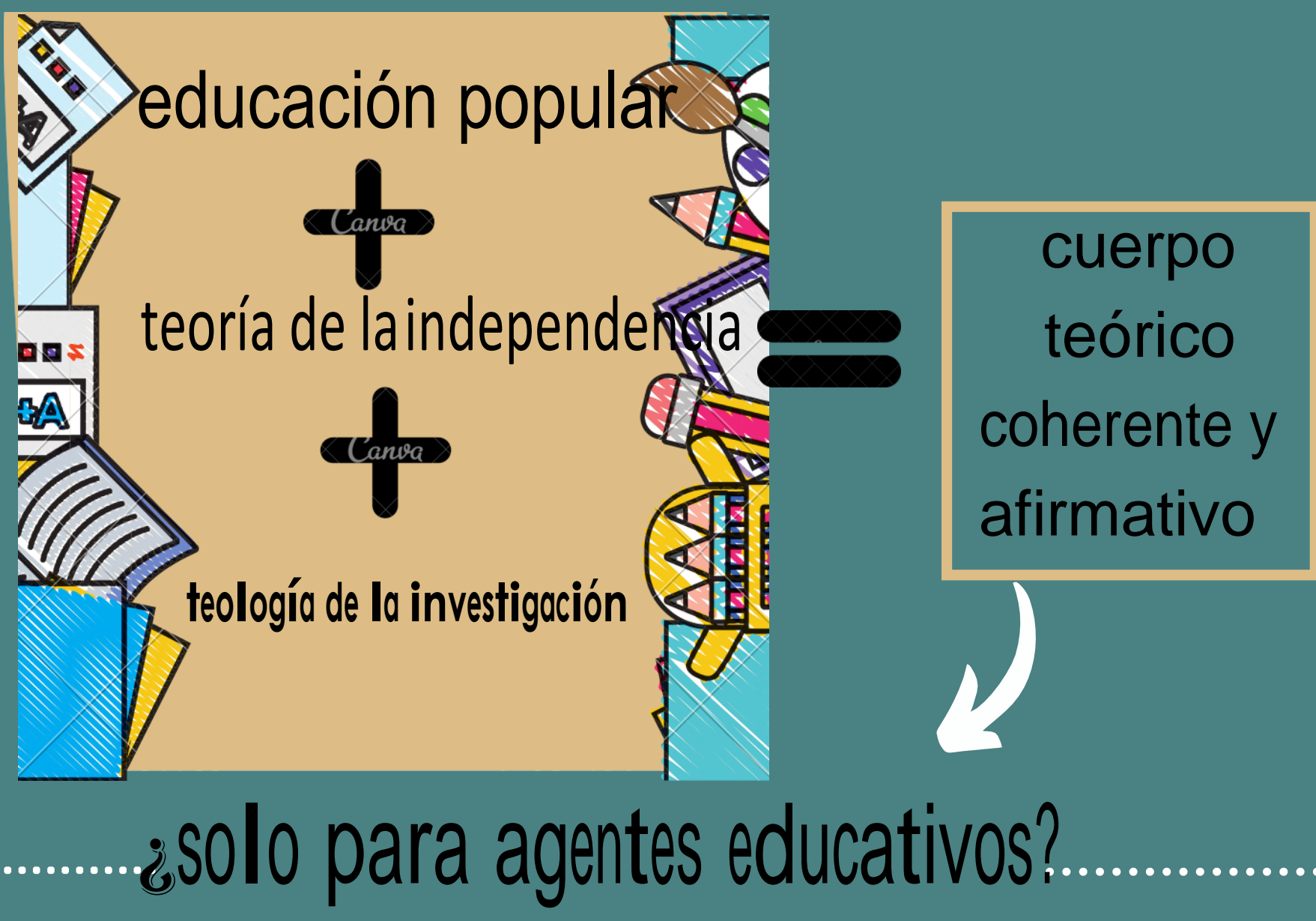

agentes educativos agentes educativos
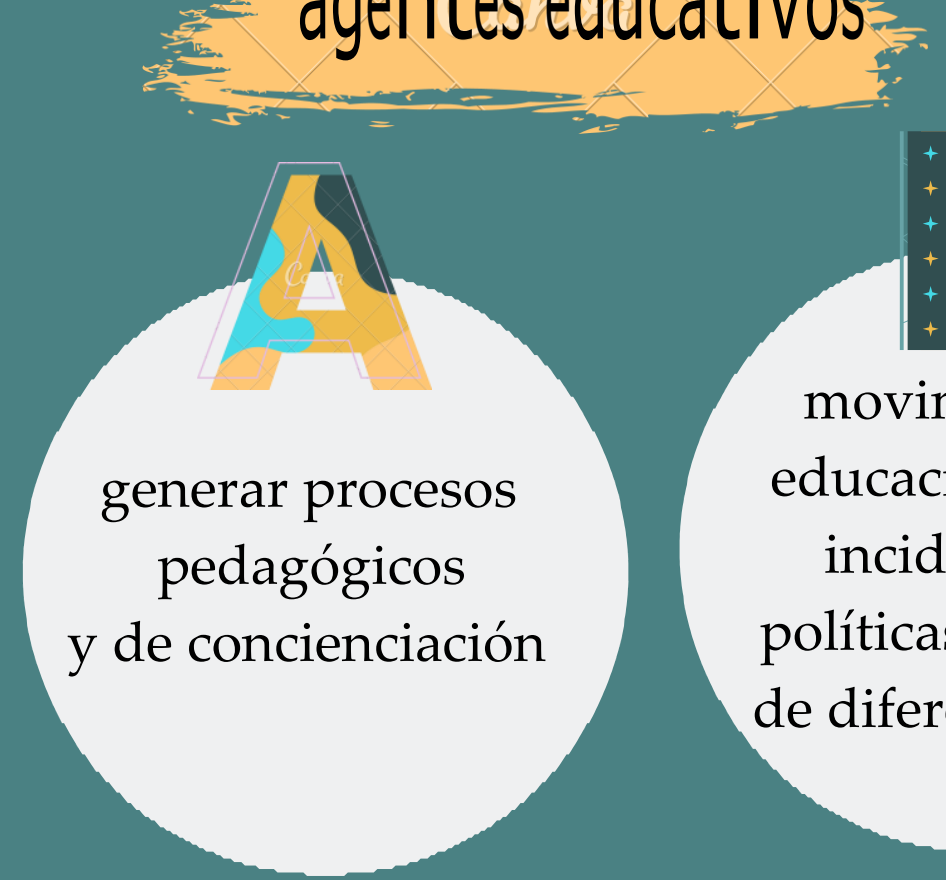

\section{sector de activistas}

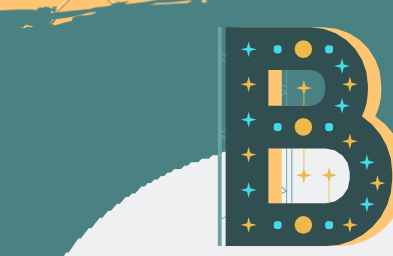

movimientos de educación popular incidían en las políticas educativas de diferentes países, se constituían en redes y organizaban diversos encuentros de ámbito internacional 
$\boldsymbol{F}_{\mathrm{n}}$ términos teóricosla sistematización surge y se alimenta de corrientes teórico-prácticas renovadoras que buscan redefinir, desdela realidad latinoamericana, los marcos de interpretación y los modelos deintervención vigentes.
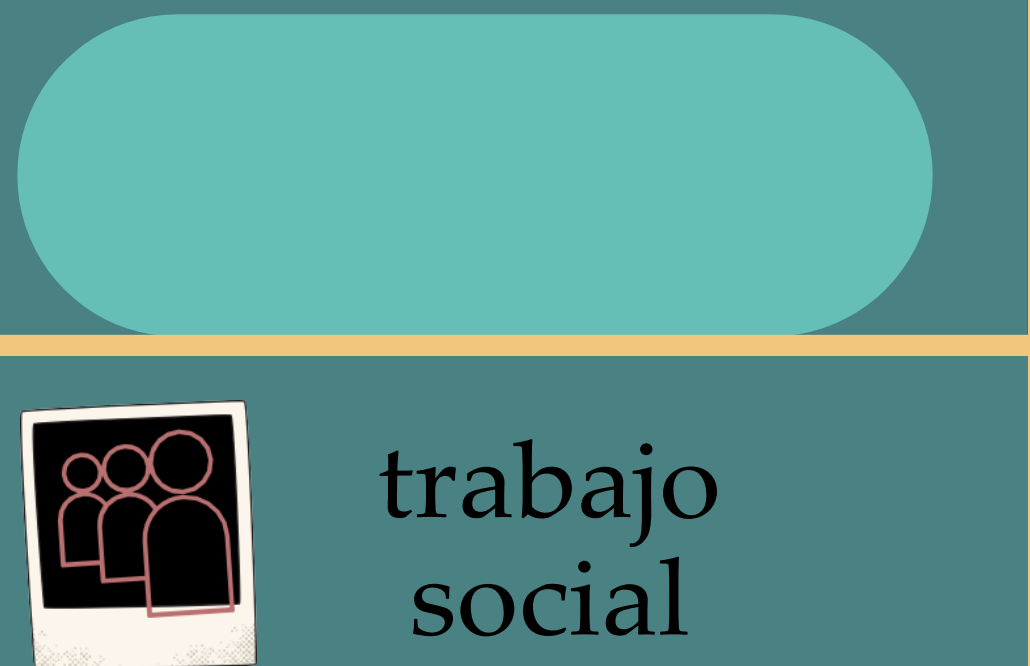

\section{trabajo social}

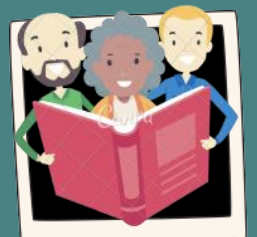

\section{teología de la liberación}

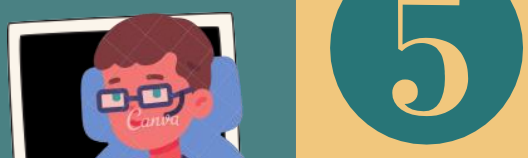

La centralidad de la práctica cotidiana y del trabajo de campo

pro-fesional como fuente de conocimiento.

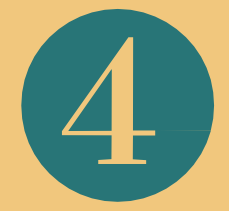

.La necesidad de superar la dicotomía entre formación teórica y aprendizaje práctico.

El interés por construir un pensamiento y una acción sustentados y orientados con rigurosidad científica.

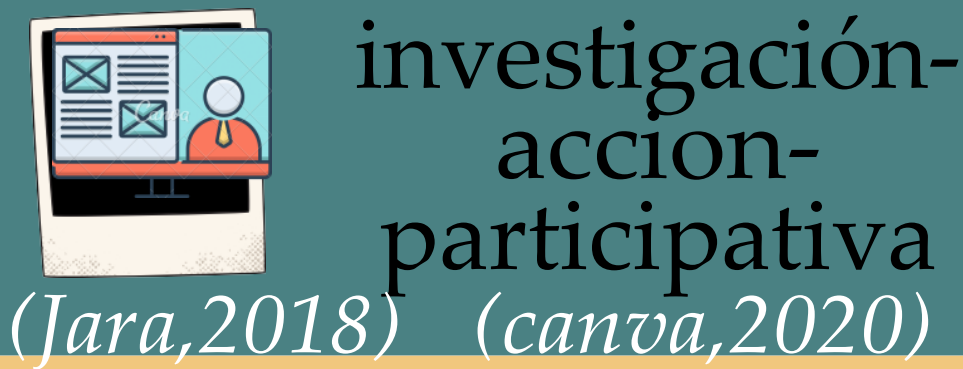




\section{CARACTERISTICAS}

conocimient

Reconstruye

o desde la

experiencia

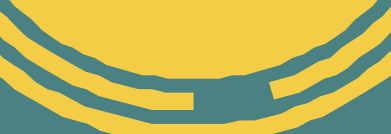

Fortalece las

capacidades personas. individuales

y en grupo las
personas.

Valorizalos 1 el proyecto y el saberes de

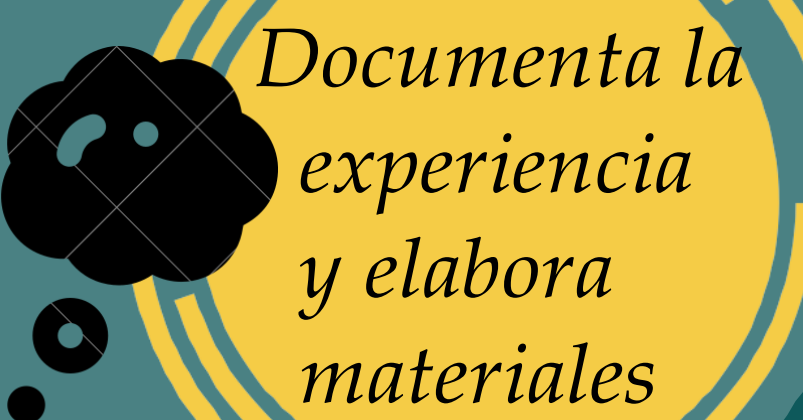

proceso contribuye a identificar las tensiones entre el proyecto y el proceso

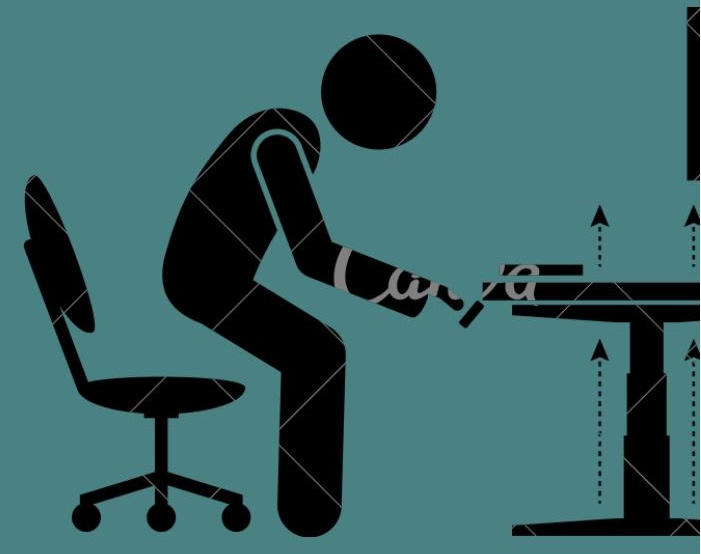

identificar las

tensiones entre

Identifica $y$ formula lecciones

(Jara,2018) (canva,2020) aprendidas 


\section{PRODUCE \\ CONOCIMIENTO DESDE \\ LA EXPERIENCIA}

permite praducin ware que canacimienta amewtede prauienen dinecta uiuida la $e x p e n i e n c i a c k e$ penda

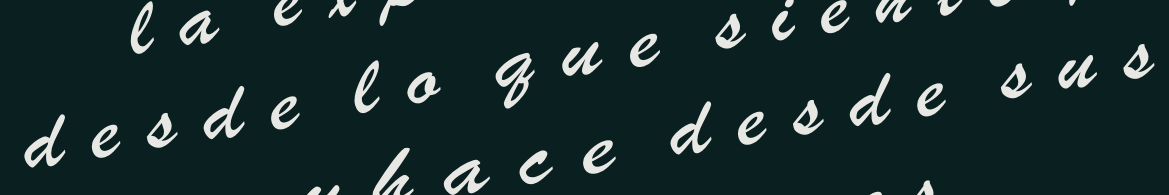
yhace decteredes.

\section{RECONSTRUYE} no setrata de ordenar $p$ reconstruir lo que sadere $s i n o$ decompromenes,

reconstruccion del procos interpretar ratones,

\section{$(J a r a, 2018) \quad($ canva,2020)}




\section{VALORIZALOS SABERES DELAS PERSONAS QUE SON SUJETO DELA EXPERIENCIA \\ paue ateucián a las}

prataqanictas dedicha - Sexpriencia.debe den el princip cajetadedudictenteracián. intenuencianes, intencianed. es. seancampantidad.

TENSIONES ENTREEL

PROYECTO YEL

PROCESO

A

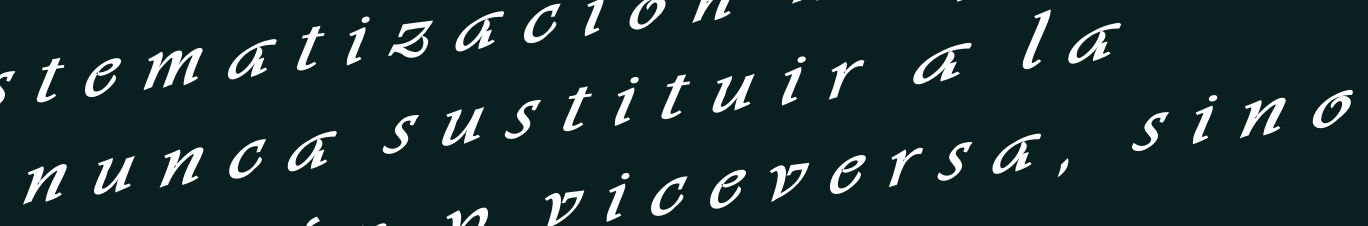
sistem atis evaluacion $v$ vicateren $($ Jara,2018) (canva,2020) mutuamente. 


\section{IDENTIFICA Y FORMULA LECCIONES
APRENDIDAS}

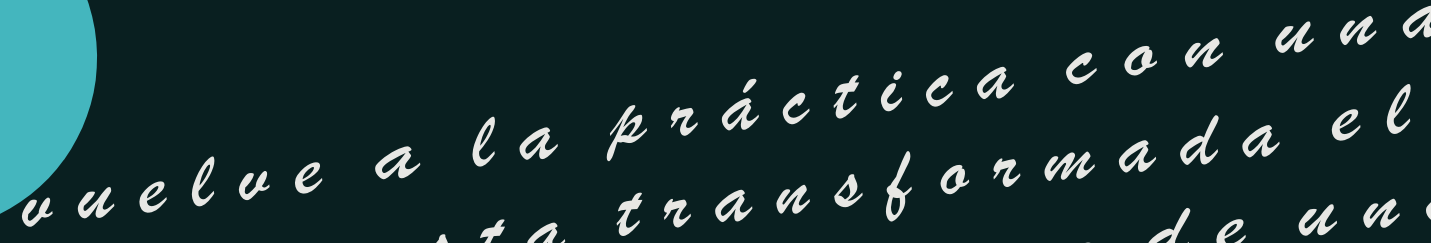

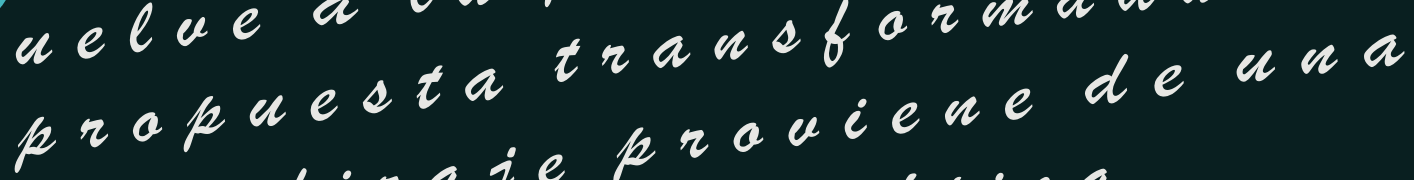
reflexián cret $x$ a

\section{DOCUMENTALA
EXPERIENCIAY
ELABORA MATERIALES}

se redacta en cuanto a gue quepensamos también hemos heoho. taba a $\operatorname{go}^{\circ}$ fotografia $y$ grata fora interesante paraionde laconstrucoion

$(J a r a, 2018) \quad($ canva,2020) $r e f l e x i \circ$ a $r$. 

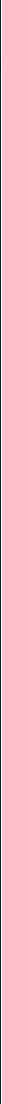

¿CÓMO SISTEMATIZAR UNA EXPERIENCIA?
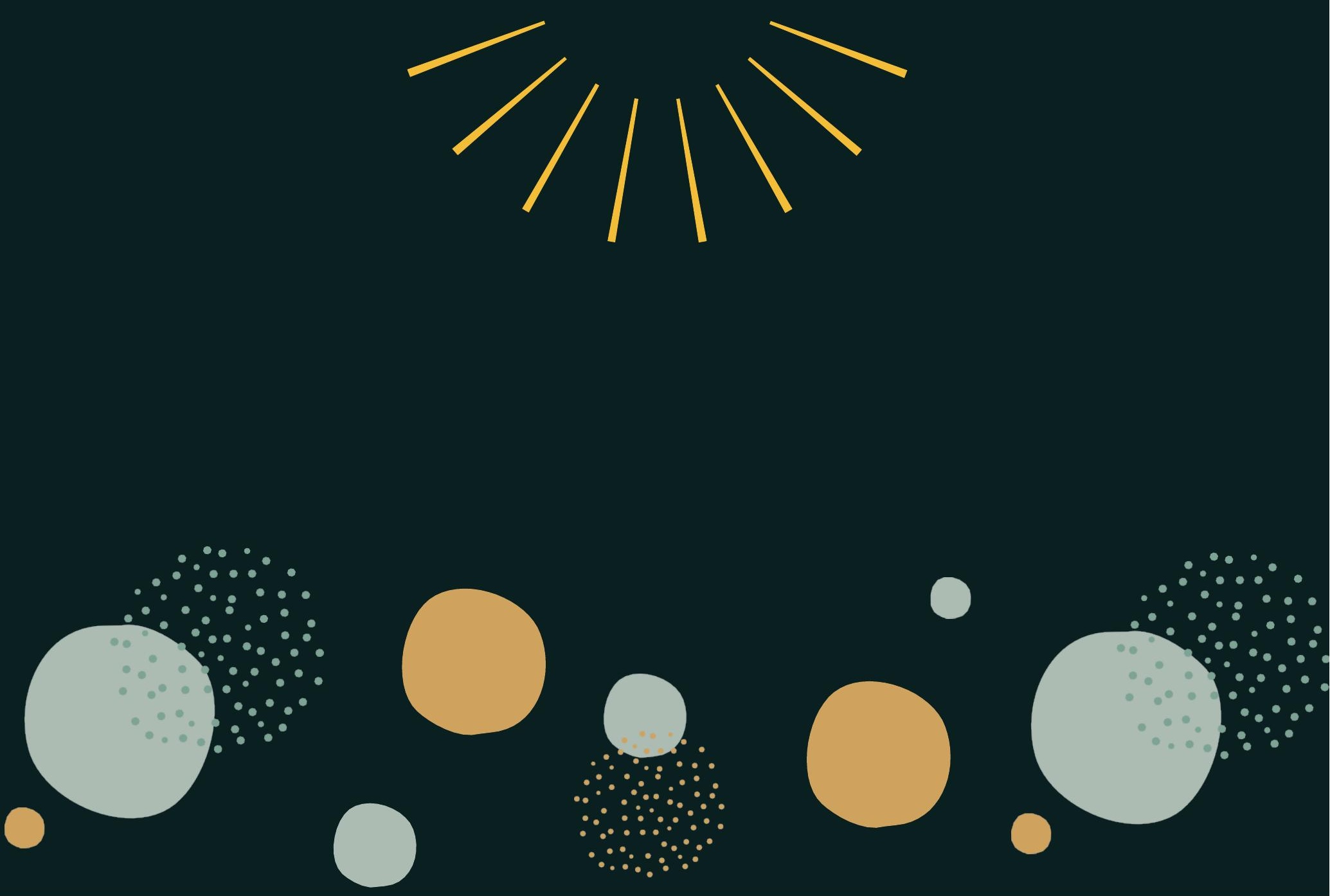


\section{¿CÓMO SISTEMATIZAR UNA EXPERIENCIA?}

Esta pregunta viene formulada muchas veces con la expectativa de encontrar como respuesta un modelo, una receta, una secuencia de pasos definidos que si seguimos fielmente nos permitirán arribar a un resultado exitoso. Eso, lamentablemente no existe.

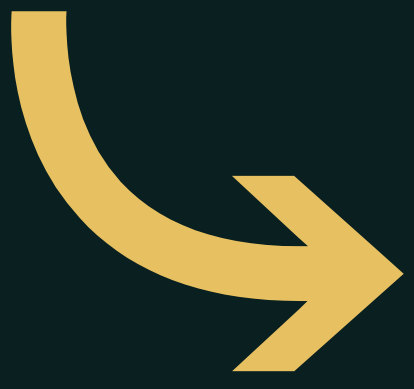

Sin embargo Jara (2018) propone un método de cinco tiempos que todo proceso de sistematización debería contener:

1.El punto de 2.Formular un partida: La experiencia sistematización | del proceso vivido 


\section{FORMULAR UN PLAN D
SISTEMATIZACIÓN}

Se trata de iniciar propiamente el proceso de sistematización. Para ello, debemos plantearnos cinco pasos fundamentales:

1. la definición del objetivo de esta sistematización
2. la delimitación del objeto a sistematizar 3.la precisión del eje de sistematización 4.la ubicación de las fuentes de información a utilizar
5. la planificación del procedimiento a seguir. 


\section{DEFINIR EL OBJETIVO DE LA SISTEMATIZACIÓN}

Para la definición de un objetivo de sistematización, debemos tener en

La misión y la estrategia de la organización, grupo o institución a la que pertenecemos, de tal manera que este ejercicio contribuya a ella.

\section{cuenta:}

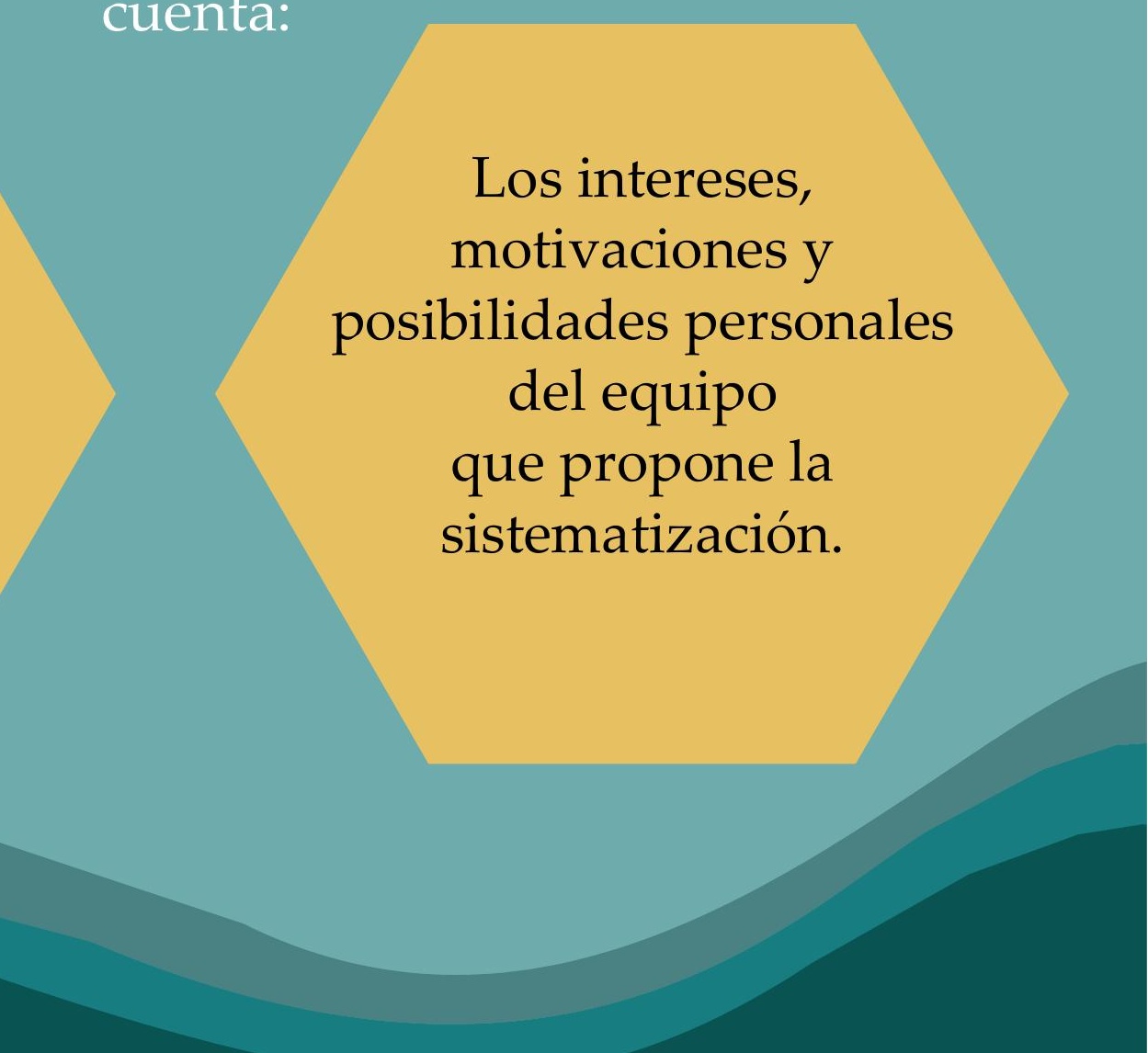

para formular el objetivo puede ser de ayuda el tener en cuenta las utilidades de la sistematización y ver a cuál campo correspondería más el resultado que se pretende conseguir:

- Paracomprender másprofundamente nuestras experiencias y así poder mejorarlas.
- Para intercambiar y compartir nuestros aprendizajes con otras experiencias similares.
- Para contribuir a la reflexión teórica con conocimientos surgidos directamente de las experiencias.

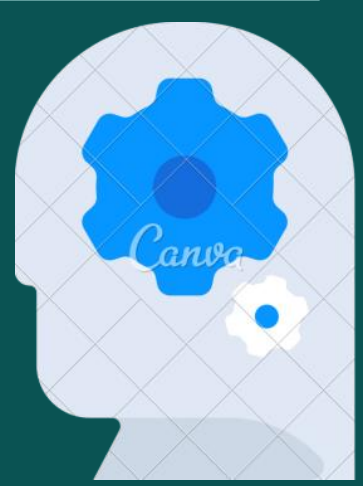




\section{DELIMITAR ELOBJETOA SISTEMATIZAR}

Consiste en escoger la experiencia concreta a sistematizar, claramente ubicada en los límites del espacio y del tiempo (es decir: dónde se realizó y en qué periodo)

\section{Interrogantes orientadores}

¿Qué experiencia vamos a sistematizar?

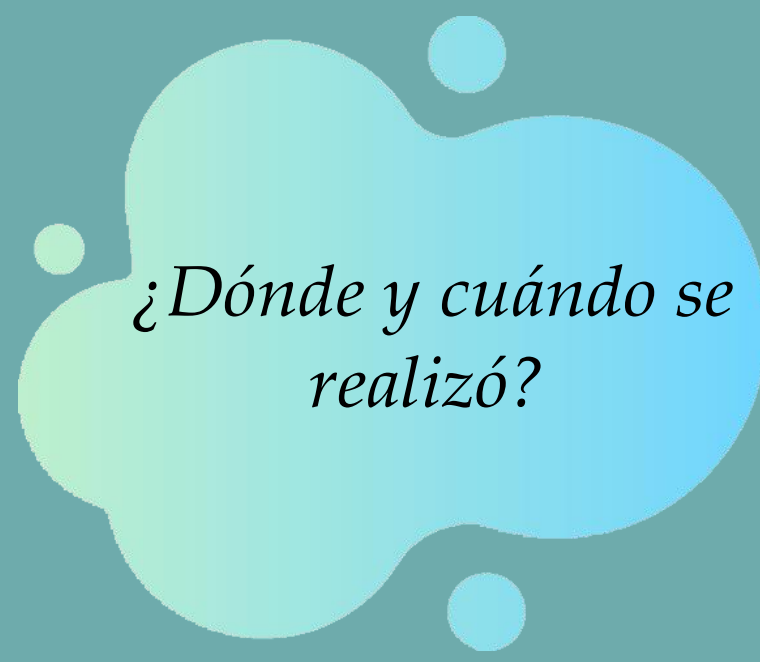

¿Sistematizaremos toda la experiencia, o solo un aspecto o parte de la misma?

¿Abarcaremos sólo un período o una etapa determinada? 


\section{PRECISAR UNEJEDE SISTEMATIZACIÓN}

En este punto, se busca precisar más el enfoque que se le quiere dar a la sistematización, para no dispersarse.

\section{Para ello se plantea:}
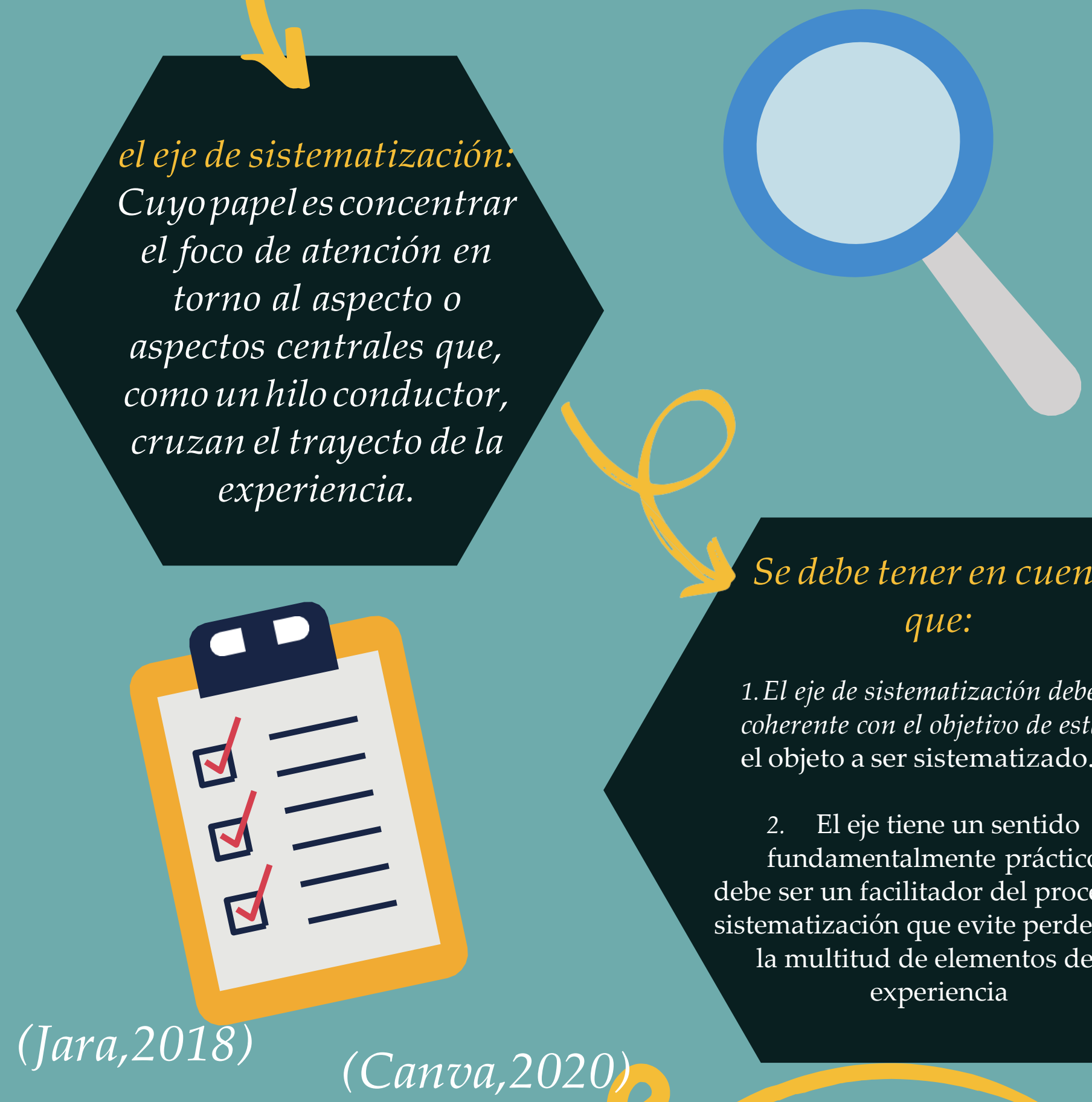

Se debe tener en cuenta que:

1. El eje de sistematización debe ser coherente con el objetivo de esta y el objeto a ser sistematizado.

2. El eje tiene un sentido fundamentalmente práctico, debe ser un facilitador del proceso de sistematización que evite perderse en la multitud de elementos de la experiencia 


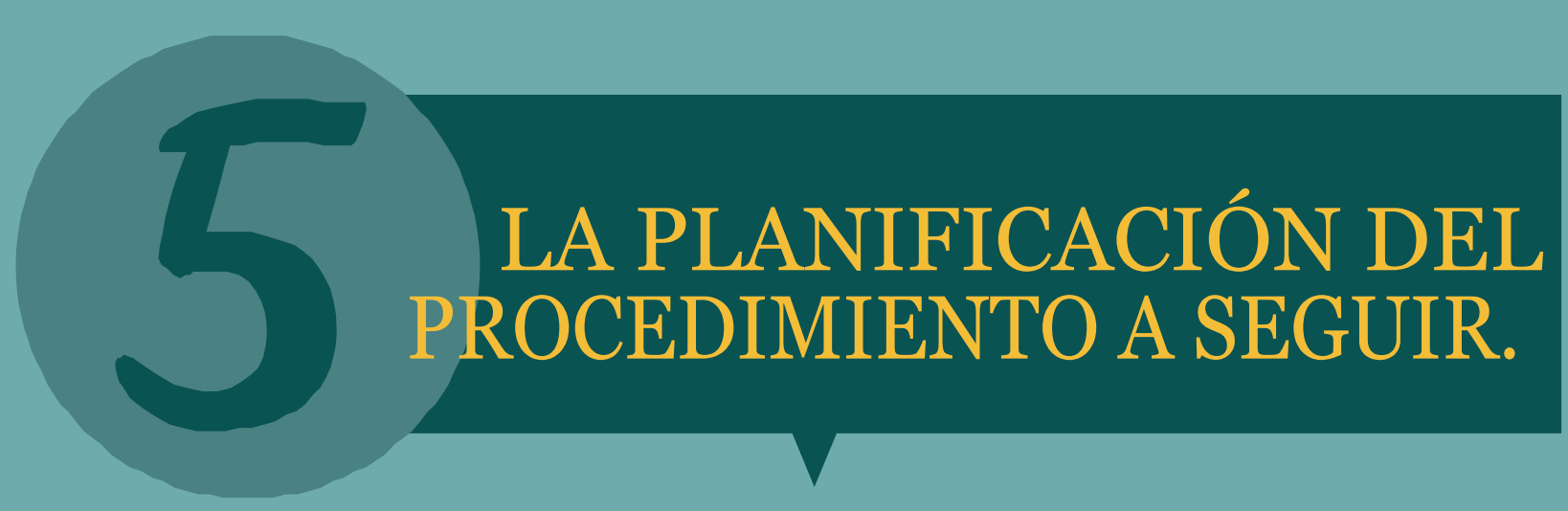

Este segundo tiempo concluye con la organización de un plan detallado de los pasos concretos que se darán para sistematizar:

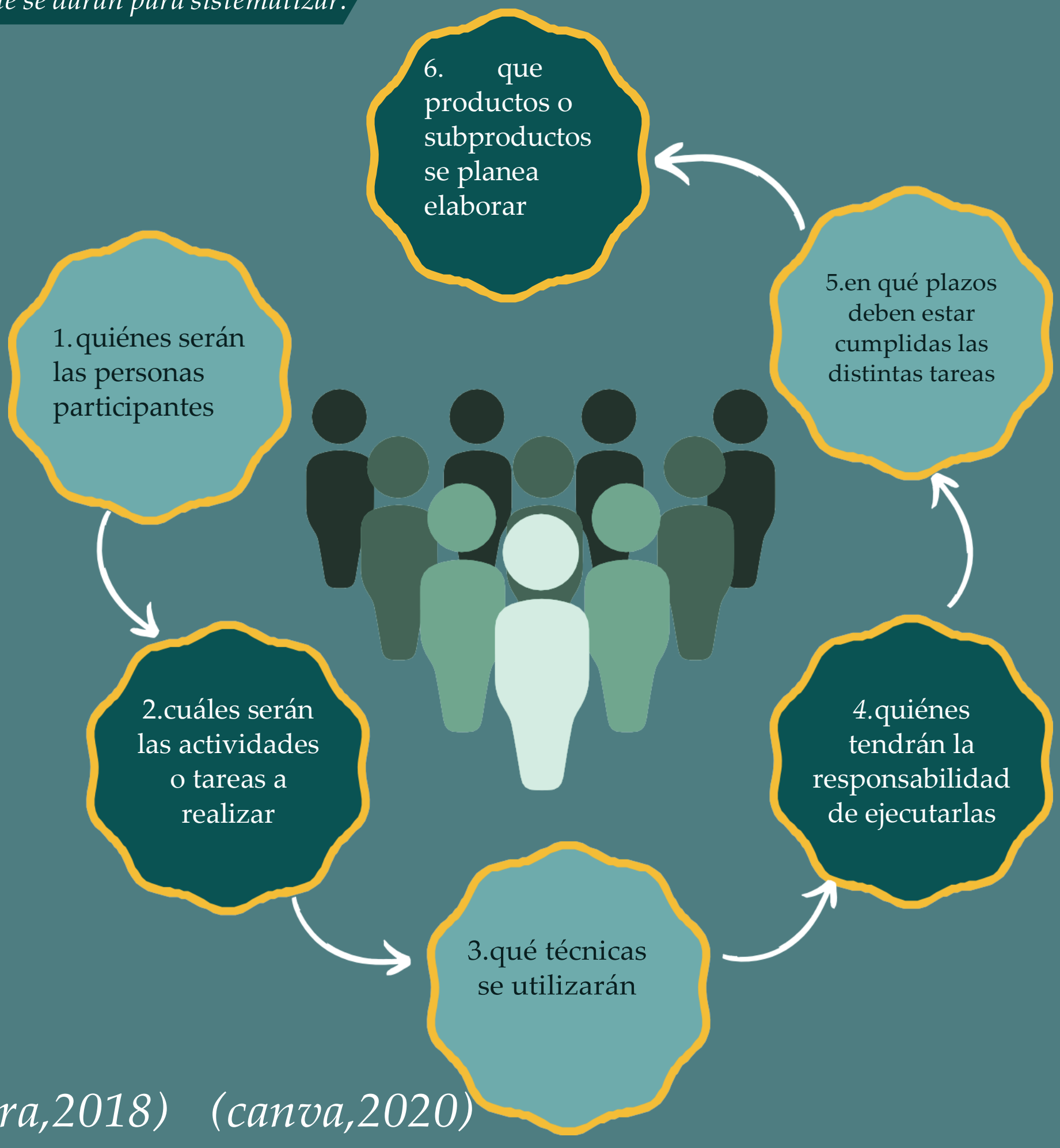

$(J a r a, 2018) \quad(c a n v a, 2020)$ 


\section{¿QUÉFUENTES DEINFORMACIÓN TENEMOS ONECESITAMOS?}

Es impartante proceder a identificar los registros con los que se cuenta, de tal manera que podamos saber si ellos nos permitirán o no acceder a la información que hará posible que arribemos a los resultados esperados.
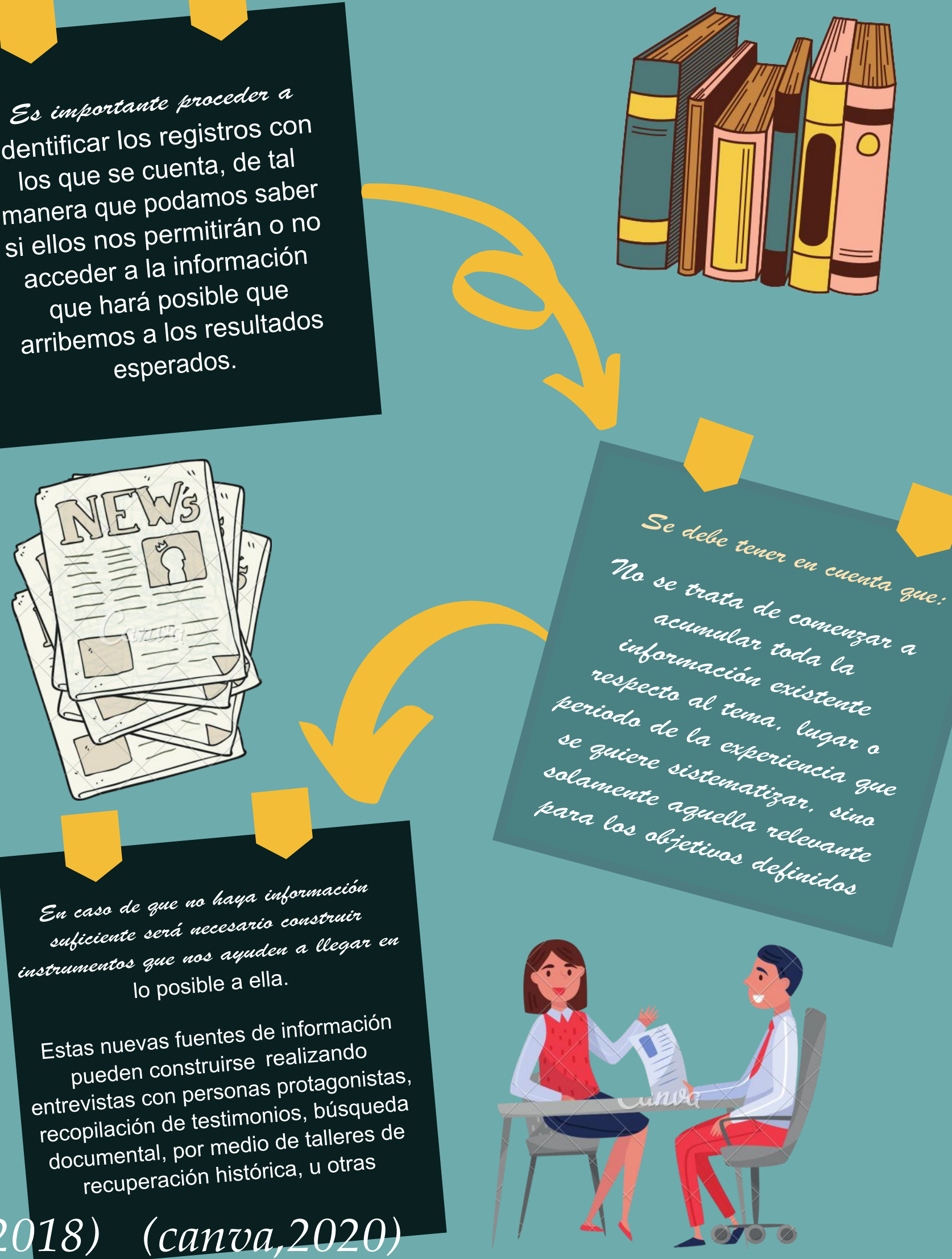

En casa de que na haya información suficiente será necesaria construir instrumentas que nos ayuden a llegar en lo posible a ella.

Estas nuevas fuentes de información pueden construirse realizando entrevistas con personas protagonistas, recopilación de testimonios, búsqueda documental, por medio de talleres de recuperación histórica, u otras 


\section{LA RECUPERACIÓN

Se trata de una exposición del trayecto de la experiencia, que nos permita objetivarla, mirando sus distintos elementos desde lejos. Es decir, tratando de no realizar aún la interpretación del porqué ocurrió cada situación, sino esforzándonos por expresarla de la forma más descriptiva posible

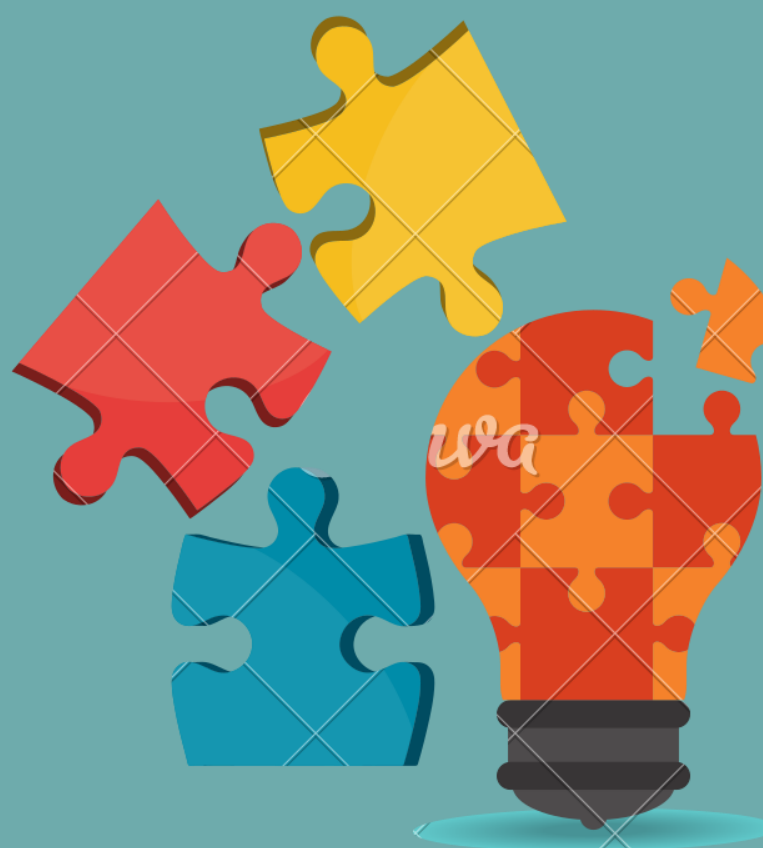

En este tiempo de la recuperación del proceso vivido debemos incluir al menos dos tareas específicas:

a) reconstruir la historia de la experiencia

b) ordenar y clasificar la información 


\section{Reconstruir la historia}

\section{de la experiencia}

Se trata de tener una visión detallada y global de los principales acontecimientos que se fueron sucediend o en el trayecto de la experiencia

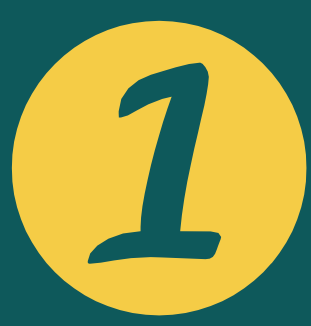

Una forma útil para reconstruir es elaborar una matriz cronológica, una línea gráfica del tiempo o un mapa de ruta recorrida con las fotografías que se han recopilado, $\mathrm{y}$ dibujos.

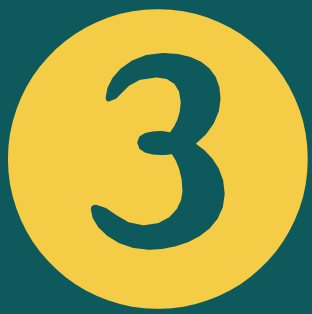

Es importante Basarnos en los registros que tenemos, para que este momento descriptivo y reconstructivo se realice a partir de dicha documentación

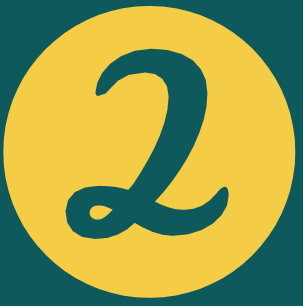

Se recomienda hacer la reconstrucción histórica principalmente de aquellos aspectos que se relacionan con el eje desistematización

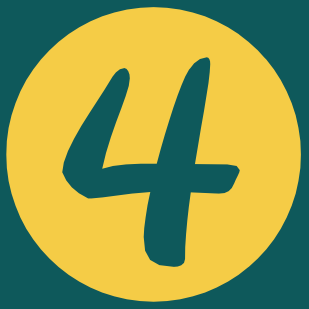

Lo más importante de la reconstrucción es que nos dé

una visión general de la experiencia como proceso, como un trayecto realizado y vivido

\section{(Canva,2020)} información

Aquí se trata de avanzar hacia la organización y ubicación de los distintos aspectos o componentes del proceso, para ello Jara (2018) nos propone seguir:

La guía de ordenamiento de aspectos

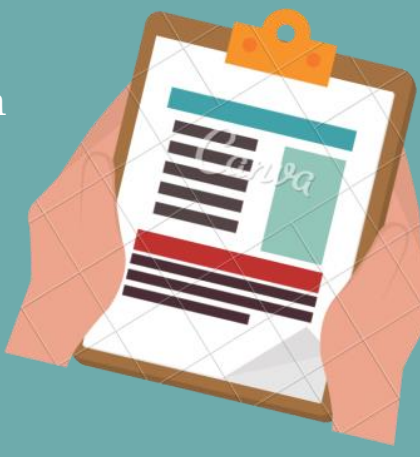
que permite clasificar (en un cuadro o en un listado) la información sobre la experiencia, separando los diferentes aspectos.

Los objetivos específicos que se formularon en cada momento
$\mathrm{S}$ motivaciones que tuvieron los participantes.
Las acciones de formación (o de animación) realizadas.
Las reacciones de las personas participantes.
Los logros y dificultades que fueron consignados en cada momento 


\section{LASREFLEXIONESDE FONDO}

Consiste en realizar un proceso riguroso de abstracción que nos lleve a descubrir la razón de ser de la experiencia a través de procesos de análisis y síntesis, que nos permitan construir interpretaciones críticas sobre lo vivido.

para realizar este proceso será necesario trabajar por se la globalidad de la esfuerzo analitico: analizar el comporita (ver sus coherencias e inconer discontinuidades, continuidades y discon ruteristicas asumida secuencias a rupturas, 10 targo del tie

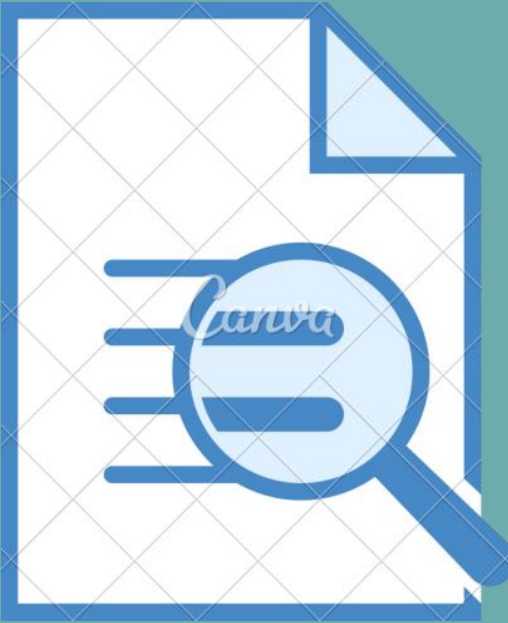

Haciendo estos ejercicios de análisis
relacionando los hallazgos que

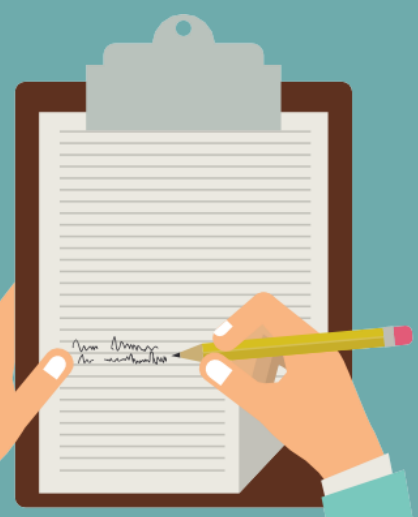




\section{Interpretación crítica}

Aquí, aspiramos a realizar una lectura crítica colectiva de la experiencia, a través de la cual podemos comprender los factores claves o fundamentales que han incidido en su trayectoria, diferenciándolos de los secundarios y accesorios.
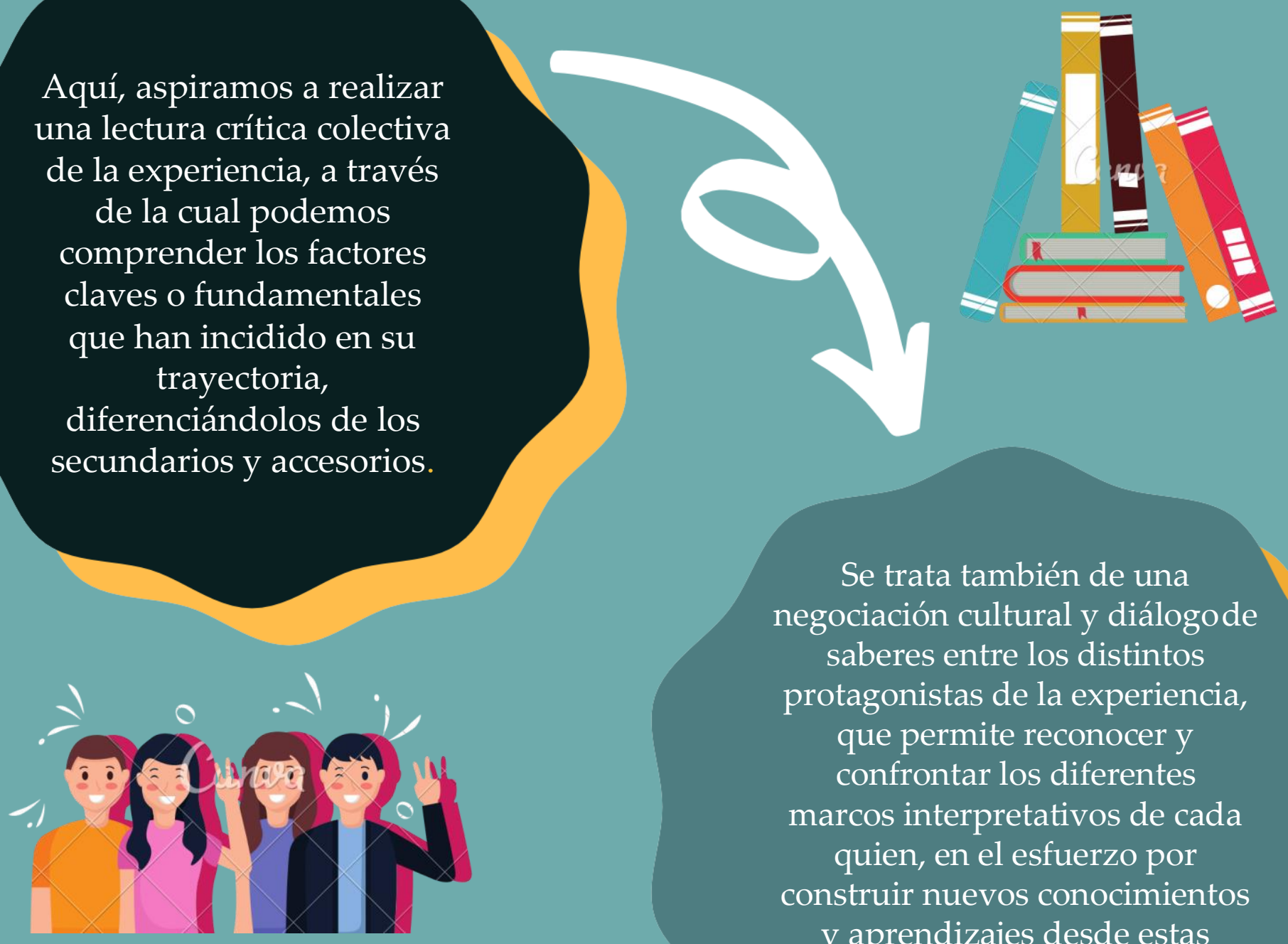

Se trata también de una negociación cultural y diálogode saberes entre los distintos protagonistas de la experiencia, que permite reconocer y confrontar los diferentes marcos interpretativos de cada quien, en el esfuerzo por construir nuevos conocimientos y aprendizajes desde estas miradas nutridas de los aprendizajes de la práctica.

Con esto, habremos producido, en este ejercicio colectivo, nuevos conocimientos provenientes de la teorización sobre nuestras experiencias y desde nuestras experiencias, pero también habremos generado sensibilidades nuevas y otras formas de percepción que antes no teníamos 


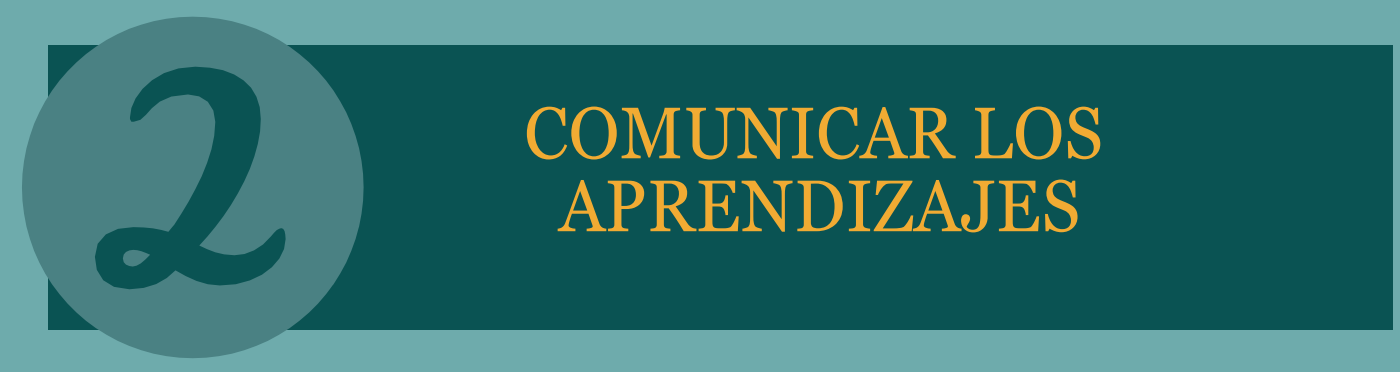

Por último, será indispensable compartir con otras personas estas conclusiones de tal forma que los principales aprendizajes no solo queden en quienes vivimos la experiencia y participamos del proceso de sistematización

en esta etapa final es importante formular toda una estrategia de comunicación pensada en función de compartir de la maneramás adecuada el proceso y los resultados con una diversidad de actores: las personas que vivieron la experiencia, otras personas

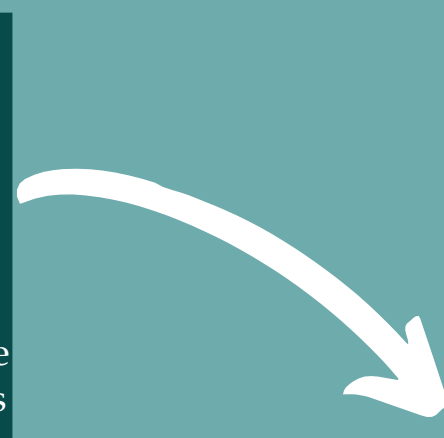
$\mathrm{u}$ organizaciones con experiencias similares, entidades que trabajan con proyectos en áreas semejantes, etc.

En esta estrategia se tendrá que definir qué contenidos se priorizan para compartir en función de a quiénes va dirigido cada material.

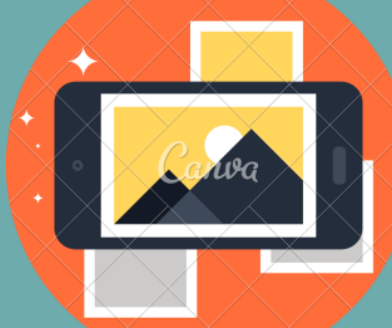

Finalmente,tratándose de compartir los aprendizajes con todas las personas involucradas en la experiencia y con otras que tienen experiencias similares, debemos recurrir a toda forma imaginativa o creativa que haga comunicable nuestra sistematización: foros de debate, obras de teatro, videos, gráficos, historietas, radiodramas, fábulas, cuentos, fichas de reflexión que contengan testimonios y aprendizajes, exposiciones fotográficas y murales, etc.
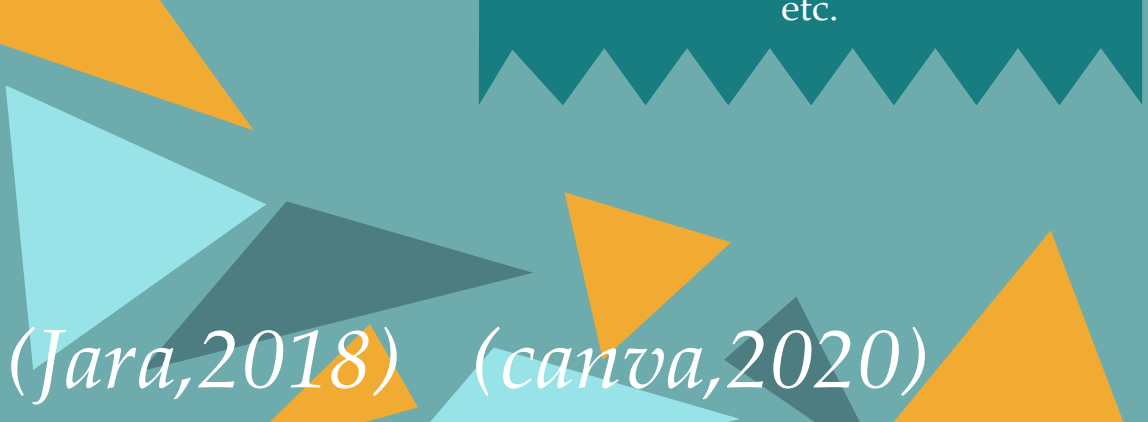

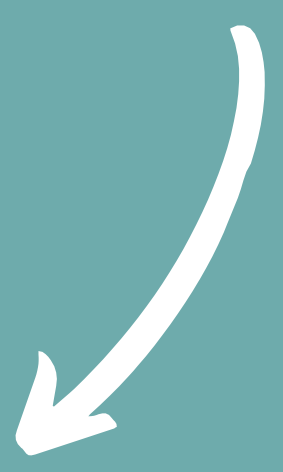



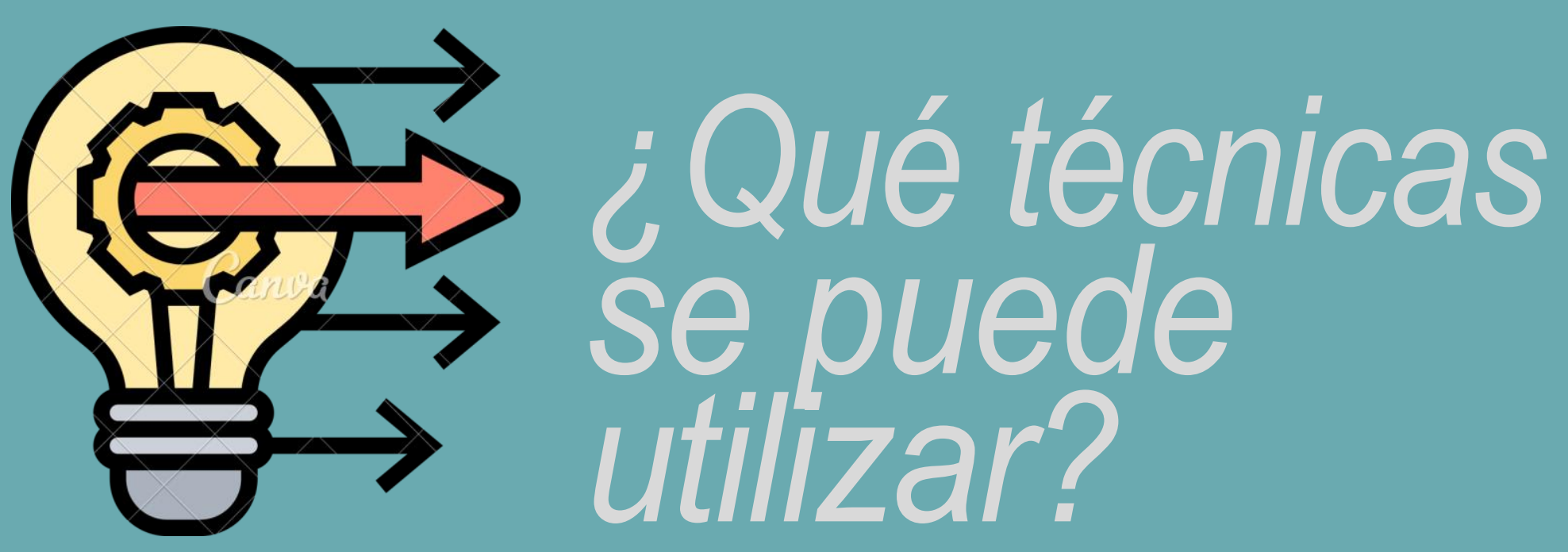

Desde una perspectiva general, la sistematización de experiencias requiere de técnicas analíticas y participativas que permitan conocer y comprender la experiencia.

Su selección y aplicabilidad dependerá de las características de cada grupo de participantes, del dominio de la temática, del espacio y del ambiente físico, de los recursos disponibles, de las destrezas y habilidades para su aplicación, de la intencionalidad pedagógica y comunicativa, de la naturaleza de la experiencia, entre otros aspectos. 


\section{¿POR QUÉTÉCNICAS ANALÍTICAS Y PARTICIPATIVAS?}
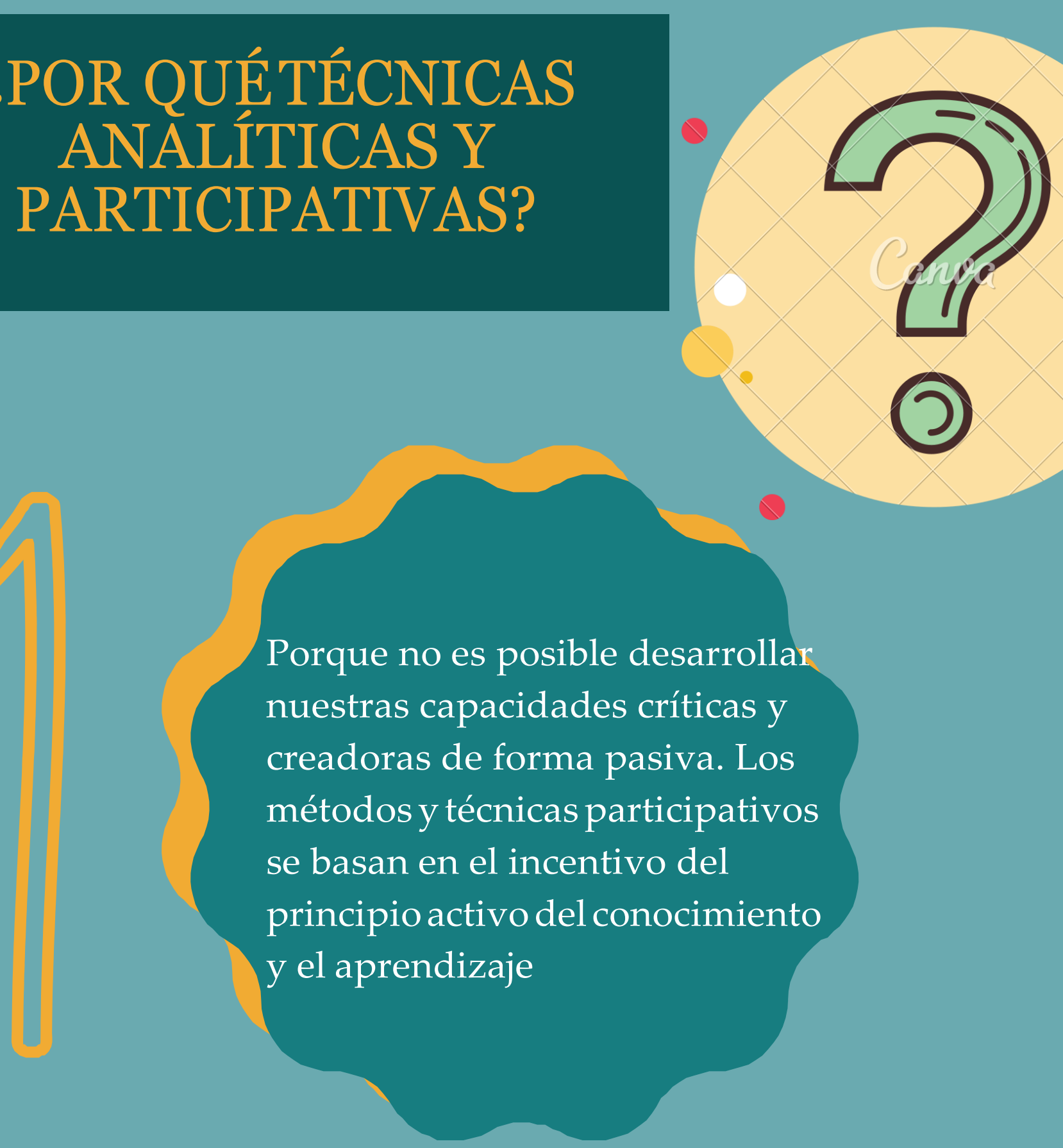

Porque como se busca relacionar la teoría con la práctica es indispensable estructurar los procesos de formación en función de las situaciones concretas que viven quienes seinvolucran en estos procesos. 



\section{CARACTERISTICAS}

Se caracterizan por crear una siteración ficticia, en la gue los DINAftICAS participantes se invalueran, reaccianan of adoptan actitudes de forma espontanea.

\section{TIPOS}


La idea es proporcionarle al grupoelementos simbólicos o simulados, con base en la actuación o representación audiovisual, que le permitan la reflexión en torno a una situación real.

\section{EJEftPLOS}

- Lluvia de ideas.

- Sociodramas.

- Juegos de roles.

- Cuentos.

- Dramatizados.

- Teatro.

- Títeres.

(Canva, 2020)

- Cine. 


\section{(c)}

\section{VISUALES}

\section{AUDITIVAS}

\section{CARACTERISTICAS}

$\backslash,|1|,||,, \mid$,

Se caracterizan por lá-

- preponderancia y

- utilización de elementos-

- gráficos-visuales 0

-auditivos-sonoros.

1,
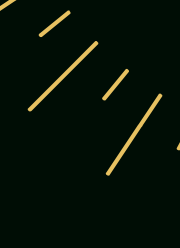

(Canva, 2020) 


\section{EJEMPLOS}

- Papelógrafos, textos, tarjetas, afiches, carteles, fotocopias, volantes.

- Presentaciones power-point,

fotografías, afiches, carteles, murales, historietas, pinturas.

- Canciones, presentaciones power-point sonorizadas, relatos, testimonios Radio foros, videoconferencias, películas, teatro, taller grupal. 


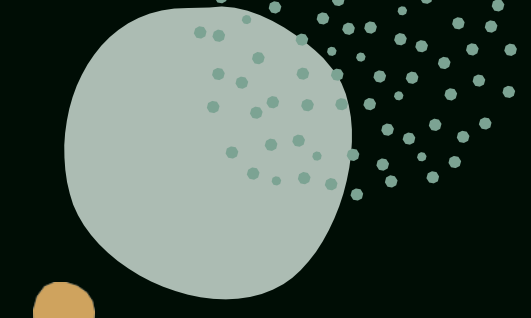

\section{.}

Historias de

vida

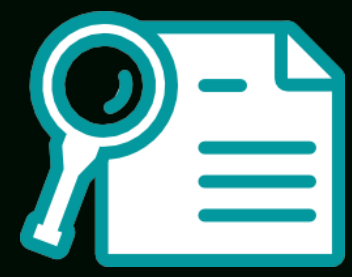

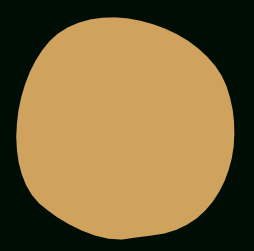

$\because \therefore \because \because \because$

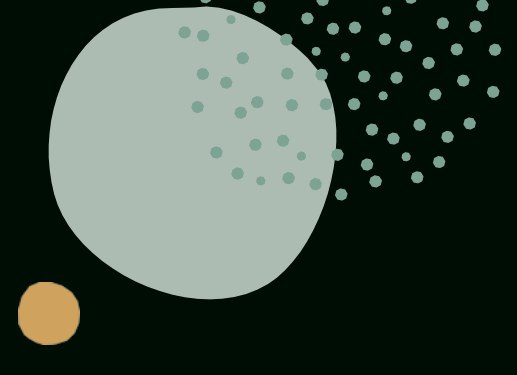

Permiten obtener un retrato completo de los hechos que secuencian la vida de las personas con el fin de obtener un perfil de las mismas a lo largo del tiempo.

La persona historiada forma parte del grupo y ha tenido una representación significativa en el desarrollo de la experiencia, a través del tiempo.

Entrevista a profundidad

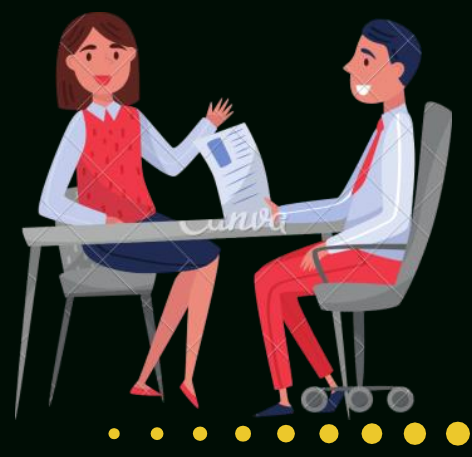

\section{Anecdotario o}

\section{incidente crítico}

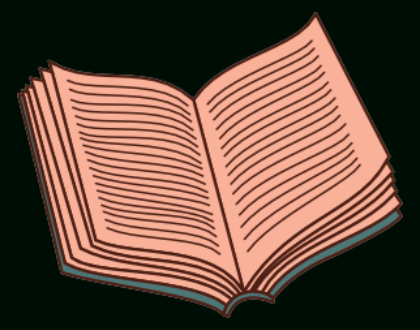

Muestras de tiempo

(Canva, 2020)
Esta técnica permite que el entrevistado, con base en un tema o en el eje central de la sistematización, exprese sus vivencias, todos sus sentimientos y pensamientos de una forma libre, espontánea y de manera conversacional. Se basa en la interacción entrevistador entrevistado y puede llevarse a cabo con grupos focales o con varios informantes directos de la experiencia.

Es un procedimiento descriptivo que fija la atención en aspectos ocurridos en determinados intervalos de tiempo. Puede representarse gráficamente a través de una línea del tiempo.

Se trata de describir episodios o anécdotas significativas vinculadas con la experiencia, expresadas en la conducta y participación del grupo o sus miembros. La idea del anecdotario es registrar lo que se ve u oye, sin enunciados interpretativos. 


\section{Re, resentaciones gráficas}

Intentan resumir los datos obtenidos. Se usan para presentar un análisis sintáctico de un episodio, situación o fenómeno observado. Igualmente sirven para poner al relieve los efectos o resultados de la experiencia y facilitan el ordenamiento de la información.

Presentacion

de matrices

Las formas de representación pueden ser descriptivas (diagramas de contexto) 0 explicativas (diagramas de dispersión, esquema de flujo, diagrama causa-efecto).

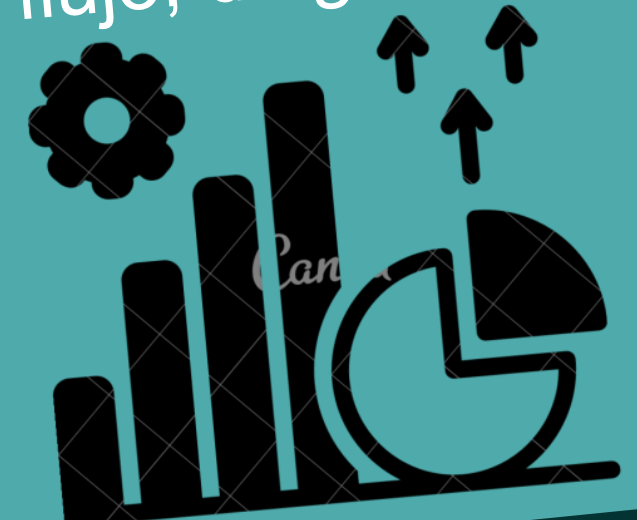



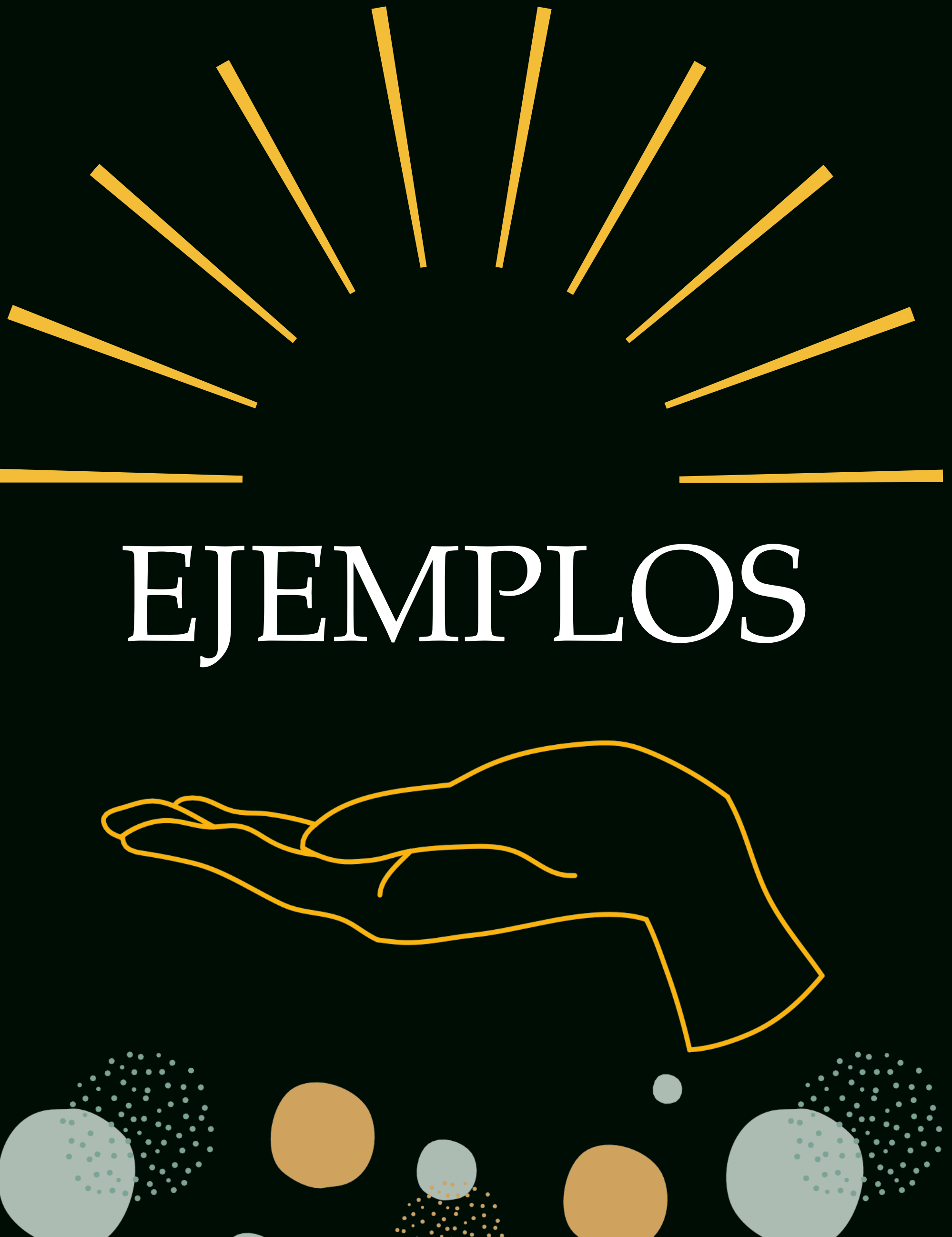


\section{LA SISTEMATIZACIÓN DE LA} EXPERIENCIA EDUCATIVA Y

ORGANIZATIVA DE LAS POBLACIONES DESARRAIGADAS DE GUATEMALA

$$
\text { (1995-1996) } 45
$$

"Esta experiencia, proceso inédito en el ámbito educativo centroamericano, se llevó a

cabo a nivel nacional en Guatemala, entre

septiembre de 1995 y octubre de 1996. En décadas pasadas, producto de la situación de represión que se vivía en el país, cientos de miles de personas, principalmente comunidades indigenas mayas, tuvieron que

migrar forzosamente de los lugares donde

vivian. Asi, se vieron obligadas a buscar otras formas de sobrevivencia, ya fuese como personas refugiadas en otros paises, o como desplazadas en el interior de Guatemala. En

esas circunstancias de desarraigo, las poblaciones crearon espacios y modalidades educativas que respondiera a sus necesidades y a las condiciones que estaban enfrentando.

Estos espacios y modalidades, a su vez, les

permitieron desarrollar capacidades y

posibilidades para el futuro"

( Holliday, 2006 ). 


\section{de lo experiencias de}

reconstrucción y desarrollo alternativo Iuego

\section{del huracán Mitch en}

\section{Centroamérica (1999-2002)}

En noviembre de 1998, el huracán Mitch, al causar los mayores estragos de dimensión regional en todo el siglo xx en Centroamérica, desnudó la precariedad delas condiciones de vida de las mayorías populares y la enorme vulnerabilidad socioambiental denuestra región. Demostró las consecuencias de la ausencia de políticas de sostenibilidad

y de un efectivo desarrollo humano integral. Una vez más, las personas más pobres fueron las más afectadas. Así, quedó demostrado que no existen desastres naturales, sino que los fenómenos naturales, como este huracán, pueden causar desastres dependiendo de las condiciones de vida de la población.
Noviembre 1998 demostró que la región centroamericana es una sola en el ámbito ambiental. Los impactos ambientales, las políticas gubernamentales, el efecto de las condiciones y políticas internacionales afectan a toda la población, una parte importante de los cientos de miles de personas afectadas por el Mitch asumieron esta situación como una oportunidad, un

desafío para la transformación de sus condiciones de vida: se organizaron para atender la emergencia, la rehabilitación, la reconstrucción y, posteriormente, buscar revertir las causas que en el futuro podrían causar estragos similares.

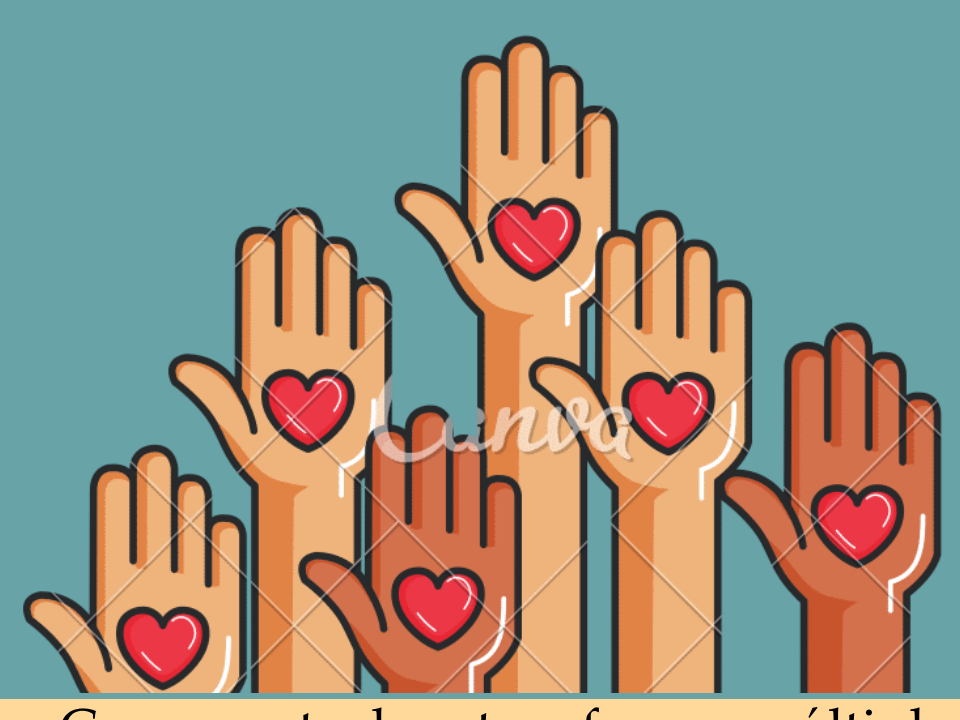

Como parte de este esfuerzo múltiple y multifacético del cual existen muchos testimonios y ejemplos, un conjunto de organizaciones sociales y ONG contrapartes de la Organización Católica Canadiense Desarrollo y Paz, contaron con el apoyo y la solidaridad inmediatas y decididas de esta organización, la cual pudo canalizar el aporte generoso del pueblo, entre otras 
SISTEMATIZACIÓN DE UNA EXPERIENCIA PEDAGÓGICA EN EDUCACIÓN ARTÍSTICA, ENUNESPACIONOCONVENCIONAL

En esta tesis se elige la sistematización como un método que abra la posibilidad de explorar el arte a partir de las experiencias que surgen en la práctica, se abordan la definición de lo que es la sistematización y el arte, $y$ "se presentan dos análisis que describen el procesos que se llevó a cabo para realizar dicha sistematización, en los cuales se muestra una descripción de los resultados que se obtuvieron según las categorías planteadas como condiciones que determinan que una práctica en el área de educación artística sea destacada" (Campos y Serrano, 2011). 
SISTEMATIZACIÓN DE EXPERIENCIAS DE ESTRATEGIAS

CAMPESINAS E INDÍGENAS EN

AMÉRICA LATINA FRENTE AL MODELO HEGEMÓNICO DE

INDUSTRIAS EXTRACTIVAS -BOLIVIA,

PERÚ, COLOMBIA, ECUADOR, HONDURAS, GUATEMALA

(2007-2008)

Este proceso de sistematización duró dos a ños y fue convocado por la red de agencias solidarias

Cooperación Internacional para el Desarrollo y la Solidaridad (cidse), quien convocó a trece de sus copartes en América Latina, que trabajan con comunidades y

organizaciones campesinas e indígenas afectadas por industrias extractivas y de producción de energía 50. Analizar y visibilizar los efectos profundos del modelo dominante de extracción de minerales y producción de energía en A mérica Latina (con un enfoque específico sobre petróleo, minas, gas y palma africana) 
SISTEMATIZACION DE EXPERIENCIAS, UN APORTE PARA LA REFLEXIÓN SOBRE LA PRÁCTICA PEDAGÓGICA EN LA LICENCIATURA EN PEDAGOGÍA INFANTIL DE UNIPAMERIC ANA

La siguiente tesis de grado refleja las elaboraciones en torno a las prácticas pedagógicas en la Licenciatura en Pedagogía Infantil de la

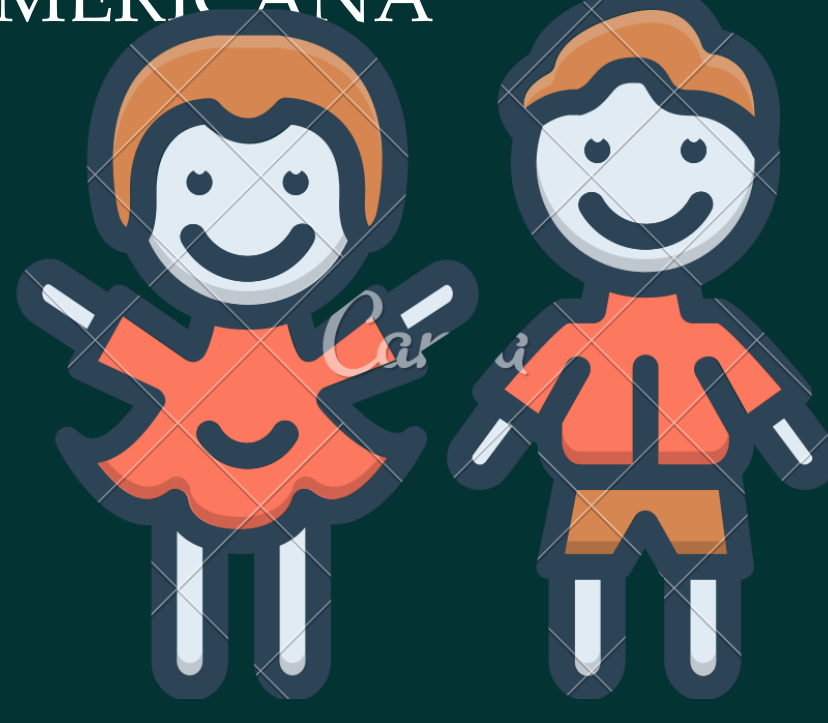
Fundación Universitaria

Unipanamericana de Bogotá.

Su estructura se centra en el enfoque deconstructivo, el cual orienta el desarrollo de cuatro momentos en los que se reflejan diversas formas de comprender y estructurar la práctica dentro de un programa de formación de Licenciados (as) estableciendo relaciones con dos procesos: la investigación y la escritura De esta manera, el ejercicio investigativo aporta a los procesos educativos en Educación Superior y a la vez explicita la fortaleza de la Sistematización de Experiencias para la visibilización, enriquecimiento, consolidación y fortalecimiento de las prácticas pedagógicas en la formación de futuros y futuras docentes.

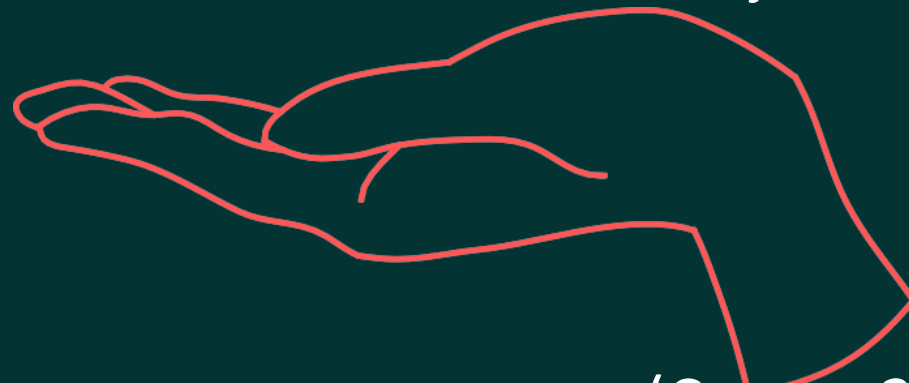




\section{REFERENCIAS}

Campos, C y Serrano,M. (2011). Sistematización de una experiencia pedagógica en educación artística, en un espacio no convencional (Tesis de pregrado). Universidad Javeriana, Colombia.

Holliday, J. (2012). Sistematización de experiencias, investigación y evaluación: aproximaciones desde tres ángulos. $F(x)=$ Educación Global Research, 1, 56-70.

Holliday, O. J. (2006). La sistematización de experiencias y las corrientes innovadoras del pensamiento latinoamericano-una aproximación histórica. Piragua,(23).

- Jara, O. (2018). La sistematización de experiencias: Práctica y teoría para otros mundos posibles. Colombia: Primera edición.

- Molano, M. A. (2016). Sistematización de experiencias, un aporte para la reflexión sobre la práctica pedagógica en la Licenciatura en Pedagogía Infantil de Unipamericana (Master's thesis).

Pérez de Maza, T. (2016). Guía Didáctica para la Sistematización de Experiencias Educativas en Contextos Universitarios. Venezuela:Ediciones del Vicerrectorado Académico.

- Perdomo Vargas, I. R., \& Rojas Silva, J. A. (2019). La ludificación como herramienta pedagógica: algunas reflexiones desde la psicología. Revista de estudios y experiencias en educación, 18(36), 161-175.

- Ruiz, L. (2001). La sistematización de práctica. Sistematización experiencia de convivencia .Recuperado de: www.oei.es/historico/equidad/liceo.PDF 